\title{
Electronic structure, stability, and cooperativity of chalcogen bonding in sulfur dioxide and hydrated sulfur dioxide clusters: a DFT study and wave functional analysis
}

Venkataramanan Natarajan Sathiyamoorthy ( $\sim$ nsvenkataramanan@gmail.com )

SHARP Substratum https://orcid.org/0000-0001-6228-0894

\section{Research Article}

Keywords: Chalcogen bond, Hydrogen bond, Non-covalent interactions, QTAIM, Cooperativity

Posted Date: July 7th, 2021

DOI: https://doi.org/10.21203/rs.3.rs-665149/v1

License: (1) This work is licensed under a Creative Commons Attribution 4.0 International License. Read Full License 


\section{Abstract}

Density functional theory calculations and wave functional analysis are used to examine the $\left(\mathrm{SO}_{2}\right) \mathrm{n}$ and $\left(\mathrm{SO}_{2}\right) \mathrm{n}-\mathrm{H}_{2} \mathrm{O}$ clusters with $\mathrm{n}=1-7$. The nature of interactions is explored by molecular electrostatic potentials, electron density distribution, atoms in molecules, noncovalent interaction, and energy decomposition analysis. The putative global minimum of $\mathrm{SO}_{2}$ molecules has a 3D growth pattern with tetrahedral. In the hydrated $\mathrm{SO}_{2}$ clusters, the pure hydrogen bond isomers are less stable than the $\mathrm{O} \cdots \mathrm{S}$ chalcogen bond isomers. The cluster absorption energy of $\mathrm{SO}_{2}$ on water increases with the size of sulfur dioxide, implying reactivity of sulfur dioxide with water increases with size. The presence of cooperativity was evident from the excellent linearity plot of binding energy/polarizability $v s$ the number of $\mathrm{SO}_{2}$ molecules. Molecular electrostatic potential analysis elucidates the reason for the facile formation of $\mathrm{S} \cdots \mathrm{O}$ chalcogen than hydrogen bonding in hydrated sulfur dioxide. Atoms in molecule analysis characterize the bonds chalcogen and $\mathrm{H}$ bonds to be weak and electrostatic dominant. EDA analysis shows electrostatic interaction is dominated in complexes with more intermolecular chalcogen bonding and orbital interaction for systems with intermolecular $\mathrm{H}$-bonding. The reduced density gradient (RDG) analysis of sulfur dioxide clusters has blue patches and green patches due to $S \cdots 0$ chalcogen bonding $0 \cdots 0$ electrostatic interaction. The RDG analysis of hydrated sulfur dioxide clusters shows intensive blue patches and green patches for the existence of $\mathrm{S} \cdots 0$ chalcogen and hydrogen bonding respectively. Thus, the presence of strong electrostatic $S \cdots O$ chalcogen interaction and weak $\mathrm{H}$ bonds acts cooperatively and stabilize the hydrated sulfur dioxide clusters.

\section{Introduction}

Sulfur dioxide $\left(\mathrm{SO}_{2}\right)$ is a primary gas molecule responsible for air pollutions. Its source of accumulation in the earth's atmosphere is being both anthropogenic and natural including volcanic eruptions [1-2]. Recently IPCC assessment report has publicized that short-term radiative $\mathrm{SO}_{2}$ exposure to the atmosphere is much more hazardous than $\mathrm{CO}_{2}$ exposure [3]. The reason for this is linked high polarity of both $\mathrm{SO}_{2}$ and water which leads to the substantial solubility of $\mathrm{SO}_{2}$ leading to the formation of sulfuric acid by an oxidation process. Because of its prominence in atmospheric implication, the interaction between water and sulfur dioxide has been the subject of many experimental and theoretical studies [4-6]. It is generally accepted that during solvation the $\mathrm{SO}_{2}$ molecules to be existent in hydrated sulfur dioxide adducts [7].

Several studies were carried out to elucidate the structure and electronic properties of $\mathrm{SO}_{2}$ monomers and dimers. The geometry of the $\mathrm{SO}_{2}$ molecule and determined its electron affinity, bond length, and angle, and vibrational frequency using photoelectron spectroscopy in solid Argon and Neon matrices were reported [8]. Very recently, using ab initio methods the structure and electronic properties of neutral and anionic ground states of $\mathrm{SO}_{2}$ molecule were reported [9]. Taleb-Bendiab et al, using microwave spectroscopy, reported the structure of $\mathrm{SO} 2$ dimer to have a low symmetry $\left(\mathrm{C}_{\mathrm{s}}\right.$-isomer) with the first $\mathrm{SO}_{2}$ unit defines a plane and the second to lie above the first [10]. The infrared spectroscopic studies on Ar matrices show a larger peak shift supporting the $C_{s}$ isomer [11]. On the contrary, in the $N_{2}$ matrix, a small shift was noticed supporting the $C_{i}$ isomer. Very recently, Ito and Hirabayashi reported $\mathrm{SO}_{2}$ dimer to subsist in $\mathrm{Cs}$ isomer in $\mathrm{Kr}$ and Xe matrices in a 
matrix-isolation study [12]. Bernstein et al. investigated the $\left(\mathrm{SO}_{2}\right)_{\mathrm{n}}$ clusters by using single-photon ionization [13]. The distribution of $\mathrm{SO}_{2}$ clusters decreases roughly exponentially with increasing cluster size.

To understand the atmospheric implication of $\mathrm{SO}_{2}$, the interaction of $\mathrm{SO}_{2}$ with water molecules was studied in gas or aqueous aerosols by both experimental and theoretical methods. Infrared and Raman studies in both gas and solution phase support the existence of $\mathrm{H}_{2} \mathrm{SO}_{3}$ to be a loosely aquated molecule $[14,15]$. To get molecular insight into the microscopic structure of $\mathrm{SO}_{2} / \mathrm{H}_{2} \mathrm{O}$ complexes several simulations were carried out, however, there persist considerable ambiguity in the structure. Born-Oppenheimer molecular dynamics simulations to investigate the hydrated structures of $\mathrm{SO}_{2}$ shows that in the gas phase and at a temperature $300 \mathrm{~K}$, the main interaction was electrostatic $\mathrm{S} \cdots \mathrm{O}$ interaction between $\mathrm{SO}_{2}$ and water [16]. However, at the surface hydrogen-bonding interaction was predominant. Microwave spectroscopy analysis suggests that $\mathrm{H}_{2} \mathrm{O}$ and $\mathrm{SO}_{2}$ form a double-decker orientation, in which the oxygen atom of water is close to the sulfur atom of the $\mathrm{SO}_{2}$ molecule [17]. Infrared spectra of $\left(\mathrm{H}_{2} \mathrm{O}\right) \mathrm{n}-\mathrm{SO}_{2}$ complexes trapped in argon matrices show hydrogen bonds for 2:1 and 3:1 complexes [18].

The calculations on the structure and energetics of $\mathrm{H}_{2} \mathrm{O} / \mathrm{SO}_{2}$ complexes were studied at the MP2 level by Cukras and Sadlej [19]. The global minima of the dimer have a double-decker orientation and the presence of strong electrostatic, dispersion, and induction interaction stabilizes the complex. The structure of sulfur dioxide with up to 8 water molecules was investigated by Studel and Steudel at B3LYP/6-31G(2df,p) level of theory [20]. $\mathrm{SO}_{2}$ resides at the surface of the water cluster, and the sulfur atom does not take part in the hydrogen-bonding network until the water molecules are less than six. The further increase in the water resulted in the isomerization of the complex to solvated furous acid. Besides the above studies, the interaction of sulfur dioxide clusters with water molecules is not known to the best of our knowledge. Although, the $\mathrm{SO}_{2}$ complexation with $\mathrm{CO}_{2}$, formaldehyde and its derivate, thioformaldehyde, and cyclohexanol were reported in which intermolecular interactions also occur through hydrogen bonding [21-24].

Gathering fundamental knowledge on the intermolecular interactions and binding topologies of biological important small molecules helps us to acquire knowledge on their role in the in-vivo process. Especially, the S...O interactions not only control molecular conformations but also affect ligand-receptor binding modes, which consecutively stabilizes the folded structures of protein and regulate the enzymatic function [25]. Among the various interactions know, the chalcogen atoms can form noncovalent complexes with electron donors $[21-23,26]$. These interactions mainly ascend near the chalcogen atom at a low electron density region that is perpendicular to the negative regions and is designated as $\pi$-hole and is tend to be highly directional [27]. Recent studies on systems with different types of interactions were found to cooperatively strengthen the each of interactions and make the complexes more stable [28-30].

The present work aims to shed light on the role of chalcogen bond cooperativity in the growth pattern, structure, and stability of sulfur dioxide and hydrated sulfur dioxide clusters. Herein, we report our systematic study on $\left(\mathrm{SO}_{2}\right) \mathrm{n}$ and $\left(\mathrm{SO}_{2}\right) \mathrm{n}-\mathrm{H}_{2} \mathrm{O}(\mathrm{n}=1-7)$ clusters using density functional theory methods. The nature of interaction and stability of the cluster are addressed using energetic analysis, molecular electrostatic potential (MEP), electron density difference (EDD), noncovalent interaction-reduced density gradient (NCI-RDG) analysis, and atoms in molecule (AIM) analysis. The cooperativity effect and the role of hydrogen bonding in 
$\left(\mathrm{SO}_{2}\right) \mathrm{n}-\mathrm{H}_{2} \mathrm{O}$ clusters in cooperativity are investigated in terms of geometry, pair-wise interaction energy, MEP and AIM analysis. Energy Decomposition Analysis (EDA) was also carried out for $\left(\mathrm{SO}_{2}\right) \mathrm{n}-\mathrm{H}_{2} \mathrm{O}$ clusters to provide insight into the role of driving forces for the hydration of sulfur dioxide clusters.

\section{Computational Details}

The initial guessed geometries for $\left(\mathrm{SO}_{2}\right) \mathrm{n}$ and $\left(\mathrm{SO}_{2}\right) \mathrm{n}-\mathrm{H}_{2} \mathrm{O}(\mathrm{n}=2-7)$ are generated using the ABCluster code, which searches the global as well as the local minima of atomic and molecular clusters [31]. For more details on the theoretical basis of the ABCluster code, the reader is referred to the work of Zhan and Dolg [32]. The coordinates obtained in the ABCluster codes are further optimized at the DFT level with the meta-hybrid GGA functional PW6B95-D3 and Def2TZVP basis set, without imposing any symmetric restrictions. Previous benchmark studies on $\left(\mathrm{SO}_{2}\right)_{2}$ by Tasinato and Grimme show that PW6B95-D3 provides the best agreement for binding energy with a mean absolute deviation of $0.3 \mathrm{kcal} \mathrm{mol}^{-1}[33]$. Recently, Malloum and Conradie found the smallest mean absolute deviation for binding energies for pronated acetonitrile clusters [34]. Harmonic frequency calculations were carried out to confirm the minimum energy structures are in real minima on the potential energy surfaces. The energies of the most stable structures were corrected for basis set superposition error using the counterpoise correction method [35]. The stability of the hydrated clusters was evaluated by calculating thermochemical quantities of model formation reaction between water as one fragment and sulfur dioxide cluster as the second fragment. The total binding energy and the incremental binding energy of the sulfur dioxide cluster are computed to assess their stability.

The total binding energy of water to the sulfur dioxide cluster is computed as

$\left.\mathrm{BE}\left(\mathrm{H}_{2} \mathrm{O}\right)=\mathrm{E}\left(\left(\mathrm{SO}_{2}\right)_{2}-\mathrm{H}_{2} \mathrm{O}\right)-\mathrm{E}\left(\mathrm{SO}_{2}\right)_{2}\right)-\mathrm{E}\left(\mathrm{H}_{2} \mathrm{O}\right)$

where $\mathrm{E}\left(\left(\mathrm{SO}_{2}\right)_{2}-\mathrm{H}_{2} \mathrm{O}\right)$ is the total binding energy of the hydrated sulfur dioxide cluster, $\mathrm{E}\left(\mathrm{SO}_{2}\right)_{2}$ is the total energy of the sulfur dioxide cluster and $\mathrm{E}\left(\mathrm{H}_{2} \mathrm{O}\right)$ is the total energy of the water molecule. All the reported DFT calculations were carried performed using the Gaussian 16 suite of programs [36].

The PW6B95-D3/Def2TZVP method was used for the construction of electrostatic potential surfaces, $\mathrm{NCI}$ analysis, and NBO analysis. The wave function analysis-surface analysis suite (WFA-SAS) program was used to calculate quantitative electrostatic potential at 0.001 electron/Bohr ${ }^{2}$ isodensity and to visualize the 3D surface [37]. The noncovalent interaction analysis ( $\mathrm{NCl}$ ) calculations were carried out with the Multiwfn program using larger grids and the isosurface is visualized using the Chemcraft program [38, 39]. Atoms in molecules (AIM) analyses were carried out using the AIMALL program package [40].

\section{Results And Discussions}

\subsection{Structures of $\left(\mathrm{SO}_{2}\right) \mathrm{n}$ clusters $(\mathrm{n}=1-7)$}

In this section, we will focus on the putative global minima (PGM) of $\left(\mathrm{SO}_{2}\right)$ n clusters $(\mathrm{n}=2-7)$, whose optimized geometries are shown in Fig. 1. The other minimum energy geometries up to 12 numbers are provided in the supporting information Fig. S1 - S6. The PGM of $\mathrm{SO}_{2}$ dimer has a low symmetry geometry 
with $\mathrm{C}_{\mathrm{s}}$ symmetry in which one of $\mathrm{SO}_{2}$ molecule is perpendicular to the other with an intermolecular $\mathrm{S} \cdots \mathrm{O}$ distance of $3.331 \AA$. The average S-O bond length in the PGM was $1.429 \AA$, which is shorter than observed for the $\mathrm{SO} 2$ molecule. By gas-phase infrared spectra study and ab initio calculations on $\mathrm{SO}_{2}$ clusters, Ito and Hirabayashi have the recommend that the PGM be stable geometry $[41,42]$. There exits two low lying geometry with $\mathrm{C}_{\mathrm{i}}$ symmetry $2 \mathrm{~S}-1$ and $2 \mathrm{~S}-2$ has a petite twist in the 0-S $\cdots 0-\mathrm{S}$ dihedral angle and are 0.55 and $0.56 \mathrm{kcal} \mathrm{mol}^{-1}$ less stable than the PGM. The $C_{2}$ symmetry geometry $2 \mathrm{~S}-3$ is $0.76 \mathrm{kcal} \mathrm{mol}^{-1}$ less stable than PGM. The existence of several low-lying isomers within a few $\mathrm{kcal} \mathrm{mol}^{-1}$ energy suggests that extreme lowtemperature studies are needed for studying the $\mathrm{SO}_{2}$ clusters.

For the trimer $\mathrm{SO}_{2}$ cluster, a cyclic ring with $\mathrm{C} 1$ symmetric with two $\mathrm{SO} 2$ molecules binding one $\mathrm{SO}_{2}$ molecule was found to be the PGM. The average S-O bond length and intermolecular S $\cdots 0$ bond lengths are $1.430 \AA$ and $3.093 \AA$ A respectively. The above values are longer and shorter than the PGM dimer cluster. The low lying isomer 3S-1 shown in Fig. S2, with a chair conformation is just $0.07 \mathrm{kcal} \mathrm{mol}^{-1}$ in energy. Besides these next four isomers were also in cyclic configuration, however, they were found to have different orientations of $\mathrm{SO}_{2}$ molecules. For example, the 3S2-2 isomer exists in chair form but the angle of orientation of $\mathrm{SO}_{2}$ differs from one other, while the $3 \mathrm{~S}-5$ isomer exists in a cup shape configuration. It is interesting to observe that the configuration other than cyclic forms such as the bent configuration (3S8-3S-11) is less stable than the cyclic configurations. Of the entire configuration, the linear $3 S-12$ was found to be the least stable.

The PGM and the 12 low-lying geometries along with selected bond parameters for the $\mathrm{SO}_{2}$ tetramer clusters are provided in Fig. 1(c) and Fig. S3 respectively. The PMG of the tetramer cluster has a tetrahedral geometry in which the $\mathrm{SO}_{2}$ molecules occupy the corners. The average $\mathrm{S}-\mathrm{O}$ bond length in these cluster remains at 1.430 $\AA$, while there is an increase in average intermolecular $\mathrm{S} \cdots 0$ bond length to $3.138 \AA$ compared to the trimer PGM cluster. The first five low-lying isomers of tetramer clusters shown in Fig. S3 (4S-1-4S-5) are found to exist in the tetrahedral geometry, with a small change in the angle of orientation of $\mathrm{SO}_{2}$ molecules. It is interesting to find that these are just $0.04-0.74 \mathrm{kcal} \mathrm{mol}^{-1}$ energy differences than the PGM. The butterfly-like configurations shown in Fig. S3 (4S-7, 4S-8, 4S-10, 4S-11) have nearly twice less stable as the tetrahedral configurations. Moreover, the planar geometry shown in Fig. S3, 4S-12 are the least stable conformers. This indicates that $3 \mathrm{D}$ growth is preferred in the $\mathrm{SO}_{2}$ clusters. It is worth point out that our previous studies on DMSO clusters show them to have ouroboros structure with 2D growth $[43,44]$.

With the increase in the number of $\mathrm{SO}_{2}$ molecules and the existence of several closely positioning isomers, the complexity of finding the PGM for larger clusters becomes more complex and computationally expensive [45]. Hence, for the pentamer to heptamer cluster, the possible guessed structures are obtained by adding one, two, and three $\mathrm{SO}_{2}$ molecules to the lowest energy tetramer and trimer clusters in all possible directions. The PGM for the pentamer is shown in Fig. 1 (d) and the low-lying isomers are shown in Fig. S4. In the pentamer to heptamer clusters, we have noticed that those $\mathrm{SO}_{2}$ molecules whose oxygen atoms both are in bonding with nearly by the sulfur atom of sulfur dioxide have a shorter $\mathrm{S} \cdots \mathrm{O}$ bond distance. The average $\mathrm{S}-\mathrm{O}$ bond length in pentamer, hexamer, and heptamer clusters remain at $1.430 \AA$, while the intermolecular $S \cdots 0$ bond distance in these clusters are $3.216,3.257$, and $3.187 \AA$ respectively. Furthermore, in these clusters, the $\mathrm{SO}_{2}$ molecules 
exist in near tetrahedron geometry when one, two, and three sulfur dioxides are removed from the pentamer, hexamer, and heptamer clusters.

\subsection{Structure of $\left(\mathrm{SO}_{2}\right) n-\mathrm{H}_{2} \mathrm{O}(\mathrm{n}=1-7)$}

The sulfur dioxide molecule can interact with hydrogen atoms in water and make a hydrogen bond or the $\pi-$ hole observed on the sulfur atom can interact with the electron-rich oxygen atom of water to make a chalcogen bonding. The PGM of $\mathrm{SO}_{2}-\mathrm{H}_{2} \mathrm{O}$ hetrodimer is shown in Fig. 2(a) and the other three low-lying isomers (SH-1, SH-2, and SH-3) are shown in Fig. S7. The PGM of $\mathrm{SO}_{2}-\mathrm{H}_{2} \mathrm{O}$ was found to have the $\mathrm{S} \cdots \mathrm{O}$ chalcogen bonding with an intermolecular distance of $2.719 \AA$. The intramolecular S-O bond length has contracted from 1.440 in the free $\mathrm{SO}_{2}$ molecule to $1.431 \AA$ in the $\mathrm{SO}_{2}-\mathrm{H}_{2} \mathrm{O}$ complex. On the contrary intramolecular $\mathrm{O}-\mathrm{H}$ distance of water got stretched from 0.957 in free water to $0.959 \AA$. This may be envisaged due to the electron density transfer from the sulfur atom to the water molecule. We noticed three low-lying isomers (SH-1, SH-2, and SH-3) with H-bonding and intermolecular distances of 2.414, 2.430, $2.168 \AA$, with $1.72,2.09$, and $2.87 \mathrm{kcal} \mathrm{mol}^{-1}$ higher than the PGM respectively. The lower stability of the H-bonded isomers shows that chalcogen bonds are stronger than the H-bonds (vide infra).

The $\left(\mathrm{SO}_{2}\right)_{2}-\mathrm{H}_{2} \mathrm{O}$ hetrotrimer can be in various isomeric forms. The PGM of the trimer cluster is shown in Fig. 2(b) and the other low-lying isomers are provided in Fig. S7. The trimer PGM has one S $\cdots 0$ chalcogen with an intramolecular distance of $2.630 \AA$, which is shorter than observed in the $\mathrm{SO}_{2}-\mathrm{H}_{2} \mathrm{O}$ cluster. The average Ow$\mathrm{H} \cdots \mathrm{O}$ distance between water and the $\mathrm{SO}_{2}$ was $2.420 \AA$, while the average intramolecular $\mathrm{S}-\mathrm{O}$ bond length was $1.432 \AA$ which is slightly higher than observed in the $\mathrm{SO}_{2}-\mathrm{H}_{2} \mathrm{O}$ cluster. The low-lying isomer $2 \mathrm{SH}-1$ has 0.78 $\mathrm{kcal} \mathrm{mol}^{-1}$ higher in energy than PGM and exist in a cyclic chair conformation with two intermolecular chalcogen bond and one hydrogen bond. The next three low-lying isomers $\mathbf{2} \mathbf{S H}-2, \mathbf{2} \mathrm{SH}-3$, and $\mathbf{2} \mathrm{SH}-\mathbf{4}$ all exist in a cyclic conformation similar to the $\mathbf{2} \mathrm{SH}-1$, but the orientation of the $\mathrm{SO}_{2}$ molecule differ in these isomers. The linear isomers $\mathbf{2} \mathrm{SH}-\mathbf{5}, \mathbf{2} \mathrm{SH}-6$, and $\mathbf{2} \mathrm{SH}-\mathbf{7}$ are less stable than the cyclic conformers. Comparison between the linear structures shows that $2 \mathrm{SH}-5$ in which the two $\mathrm{SO}_{2}$ molecules has chalcogen bond with water molecule is more stable than structures where there exists intermolecular chalcogen bonding between $\mathrm{SO}_{2}$ molecules as in 2SH-6 and 2SH-7. From the above discussion, we can conclude that the structures which exist with chalcogen bonding alone and with only $\mathrm{H}$-bonding are less stable and the existence of cooperativity between these two bonding's helps in stabilizing the PGM of $\mathrm{SO}_{2}$-water clusters.

The PGM of the hetrotetramer cluster occurs with two $\mathrm{SO}_{2}$ molecules in hydrogen bonding with water and the other $\mathrm{SO}_{2}$ to be in chalcogen $\mathrm{S} \cdots \mathrm{O}_{\mathrm{w}}$ bonding with water as shown in Fig. 2(c). Interestingly, the molecules occupy the corners in a tetrahedral geometry. The $\mathrm{SO}_{2}$ molecules are in intermolecular bonding with one another. The average intermolecular S-O bond length is shorter than the hetrotrimer but longer than the pristine $\mathrm{SO}_{2}$ molecule. Furthermore, the intermolecular $\mathrm{H}$-bonds between water and $\mathrm{SO}_{2}$ got reduced to $2.161 \AA$ compared to the $2.419 \AA$ A observed for the hetrotrimer cluster. The low-lying isomers of hetrotetramer are shown in Fig. S8. One may notice that all the low-lying hetrotetramer clusters have both hydrogen bonding and one or two chalcogen $\mathrm{S} \cdots \mathrm{O}_{\mathrm{w}}$ bondings with water. The PGM clusters of hetropentamer and hetrohexamer are shown in Fig. 2(d) and 2(e) have three intermolecular $\mathrm{H}$-bonding and one $\mathrm{S}-\mathrm{O}_{\mathrm{w}}$ bonding with water. The 
PGM clusters of hetroheptamer and hetrooctamer have three intermolecular $\mathrm{H}$-bonding two chalcogen $\mathrm{S}-\mathrm{O}_{\mathrm{w}}$ bonding with the water molecule.

\subsection{Energetics of $\left(\mathrm{SO}_{2}\right) \mathrm{n}$ and $\left(\mathrm{SO}_{2}\right) \mathrm{n}-\mathrm{H}_{2} \mathrm{O}(\mathrm{n}=1-7)$}

To understand the stability of the $\mathrm{SO}_{2}$ and hydrated $\mathrm{SO}_{2}$ clusters, we have computed their total binding energy, the average binding energy per $\mathrm{SO}_{2}$ molecule, and the incremental binding energy. The total binding energy is obtained as the difference in total energy of the cluster with the size of the cluster multiplied by the total energy of the optimized $\mathrm{SO}_{2}$ molecule. The incremental binding energy is computed as shown in bellow

$\mathrm{IBE}=\mathrm{E}\left(\mathrm{SO}_{2}\right) n-\mathrm{E}\left(\mathrm{SO}_{2}\right) n-1-\mathrm{E}\left(\mathrm{SO}_{2}\right)$

where $\mathrm{E}\left(\mathrm{SO}_{2}\right) n$ is the total energy of the sulfur dioxide cluster, $\mathrm{E}\left(\mathrm{SO}_{2}\right) n-1$ is the total energy of $\mathrm{n}-1$ th cluster and $\mathrm{E}\left(\mathrm{SO}_{2}\right)$ is the energy of the sulfur dioxide monomer. The computed energy parameters for the sulfur dioxide clusters are provided in Table 1 . The computed binding energy and binding energy per $\mathrm{SO}_{2}$ molecule for the sulfur dioxide cluster increases monotonically with the increase in the cluster size. The incremental binding energy decreases with the increase in cluster size and nears the saturation limit.

Table 1

Binding energy $(\mathrm{BE})$, binding energy per $\mathrm{SO}_{2}$ molecule $(\mathrm{BE} / \mathrm{n})$, incremental binding energy (IBE), polarizability (a) for $\mathrm{SO}_{2}$ and hydrated $\mathrm{SO}_{2}$ cluster and cluster adsorption energy (CAE) for hydrated clusters. All the energies are in $\mathrm{kcal} \mathrm{mol}^{-1}$.

\begin{tabular}{|c|c|c|c|c|c|c|c|c|c|}
\hline \multirow[t]{2}{*}{$n$} & \multicolumn{4}{|l|}{$\left(\mathrm{SO}_{2}\right) \mathrm{n}$} & \multicolumn{5}{|c|}{$\left(\mathrm{SO}_{2}\right) \mathrm{n}-\mathrm{H}_{2} \mathrm{O}$} \\
\hline & $\mathrm{BE}$ & $\mathrm{BE} / \mathrm{n}$ & IBE & $a(a . u)$ & BE & $\mathrm{BE} / \mathrm{n}$ & IBE & CAE & a (a.u) \\
\hline 1 & - & - & - & 21.15 & -5.86 & -5.86 & -5.86 & -5.86 & 29.65 \\
\hline 2 & -19.37 & -9.69 & -19.37 & 42.82 & -13.71 & -6.86 & -13.71 & -9.98 & 52.30 \\
\hline 3 & -32.84 & -10.95 & -13.46 & 66.55 & -20.70 & -6.90 & -6.99 & -11.32 & 75.90 \\
\hline 4 & -47.14 & -11.79 & -14.30 & 90.06 & -27.77 & -6.94 & -7.07 & -11.91 & 98.28 \\
\hline 5 & -62.09 & -12.42 & -14.95 & 111.14 & -33.76 & -6.75 & -6.00 & -10.78 & 122.18 \\
\hline 6 & -74.84 & -12.47 & -12.75 & 132.60 & -40.16 & -6.69 & -6.40 & -12.25 & 145.44 \\
\hline 7 & -89.78 & -12.83 & -14.95 & 156.91 & -47.81 & -6.83 & -7.65 & -12.77 & 166.10 \\
\hline
\end{tabular}

For the hydrated sulfur dioxide clusters, the binding energy increases monotonically, while the binding energy per $\mathrm{SO}_{2}$ shows no regular trend. The IBE of hydrated sulfur dioxide clusters shows the increase in the values with the cluster size except for the hetrohexamer with five $\mathrm{SO}_{2}$ molecules. The cluster adsorption energy is a useful parameter to understand the adsorption of sulfur dioxide cluster onto the water molecule which is computed as

$\mathrm{CAE}=\mathrm{E}\left(\left(\mathrm{SO}_{2}\right) n-\mathrm{H}_{2} \mathrm{O}\right)-\mathrm{E}\left(\mathrm{H}_{2} \mathrm{O}\right)-\mathrm{E}\left(\left(\mathrm{SO}_{2}\right) \mathrm{n}\right)$ 
where $\left.\mathrm{E}\left(\mathrm{SO}_{2}\right) n-\mathrm{H}_{2} \mathrm{O}\right)$ is the total energy of the hydrated sulfur dioxide cluster, $\mathrm{E}\left(\mathrm{H}_{2} \mathrm{O}\right)$ is the total energy of the water molecule, and $\mathrm{E}\left(\left(\mathrm{SO}_{2}\right) \mathrm{n}\right)$ is the total energy of the sulfur dioxide cluster. The cluster adsorption energy increase with the sulfur dioxide cluster size and reaches a near saturation. This implies that small sulfur dioxide clusters get adsorbed onto the water molecule more efficiently than the larger clusters.

The comparison of energetic parameters between $\mathrm{SO}_{2}$ and hydrated $\mathrm{SO}_{2}$ clusters would help in understanding their relative stability and reactivity. Compared to the binding energy of the pristine $\mathrm{SO}_{2}$ cluster, the hydrated $\mathrm{SO}_{2}$ cluster has $53-70 \%$ lower values. Similarly, the incremental binding energy of hydrated $\mathrm{SO}_{2}$ clusters is nearly half the value observed for the pristine $\mathrm{SO}_{2}$ clusters. This shows that hydrated $\mathrm{SO}_{2}$ clusters are relatively less stable and are more reactive.

The plot of the total binding energy $v s$ the number of $\mathrm{SO}_{2}$ molecules for the pristine $\mathrm{SO}_{2}$ and hydrated $\mathrm{SO}_{2}$ clusters are shown in Fig. 3(a) and (b), which have a perfect linear correlation with a coefficient of 0.999. Previous studies on acetonitrile and interhalogen derivatives account such behavior to the existence of cooperatively in those clusters $[46,47]$. It is worth specifying that in the absence of cooperativity, the binding energy variation would be minimal and will be closer to the binding energy of the dimer cluster. Recently, Bartkowiak et.al found that in formamide and $\mathrm{HCN}$ clusters the computed mean polarizabilities show exceptional linearity with the cluster size $[48,49]$. Our previous studies on linear DMSO clusters also show the existence of cooperativity when the mean polarizability is plotted as a function of cluster size [42, 43]. To test the above hypothesis, we plotted the polarizability as a function of cluster size for pristine and hydrated $\mathrm{SO}_{2}$ clusters as shown in Fig. $\mathbf{3 ( c )}$ and $\mathbf{3 ( d )}$, and observed excellent linearly with a correlation coefficient of 0.999, indicating the existence of cooperativity in these clusters.

One can also examine the presence of cooperativity in these clusters by computing their pairwise interaction energies [50]. The pairwise energies for the trimer to heptamer for $\mathrm{SO}_{2}$ clusters and dimer to octamer in hydrated sulfur dioxide clusters and their results are presented in Tables 2 and 3 respectively, while their numbering pattern is provided in Figs. 1 and 2. In the sulfur dioxide trimer, the interaction between $(\mathrm{I}, \mathrm{II})$ is higher than the other two pairs. It is interesting to observe the $\mathrm{SO}_{2}$ molecule I have the maximum bonding with the nearby cluster. A similar observation has been noticed in the tetramer cluster, wherein the interaction energy is higher from the (II, III) in with II has maximum bonding than the other molecules. In the pentamer cluster, the highest interaction is observed for the pair (I, II) and the least interaction occurs between the pair (II, $\mathrm{V})$ are at the nonbonding distance. In the hexamer and heptamer clusters, pair (III, IV) and (V, VI) which are in close contact and with maximum bonding have the highest interaction energy. The least interaction energies for the above clusters are for the pairs which are at the nonbonding distances. 
Table 2

Pairwise interaction energies $\left(\mathrm{kcal} \mathrm{mol}^{-1}\right)$ of the trimer, tetramer, pentamer, hexamer and heptamer for sulfur dioxide clusters

\begin{tabular}{|c|c|c|c|c|c|}
\hline Pair & Trimer & Tetramer & Pentamer & Hexamer & Heptamer \\
\hline I, II & -18.74 & -18.03 & -18.67 & -18.53 & -16.99 \\
\hline I, III & -18.18 & -18.08 & -17.55 & -15.77 & -15.63 \\
\hline I, IV & - & -17.72 & -18.60 & -15.48 & -15.68 \\
\hline I, V & - & - & -18.15 & -17.96 & -17.79 \\
\hline $\mathrm{I}, \mathrm{VI}$ & - & - & - & -16.56 & -16.50 \\
\hline $\mathrm{I}, \mathrm{VII}$ & - & - & - & - & -18.29 \\
\hline II, III & -18.26 & -18.93 & -18.18 & -16.52 & -18.13 \\
\hline II, IV & - & -17.64 & -16.88 & -17.74 & -15.69 \\
\hline II, V & - & - & -15.71 & -17.19 & -15.81 \\
\hline $\mathrm{II}, \mathrm{VI}$ & - & - & - & -18.08 & -18.26 \\
\hline II, VII & - & - & - & - & -18.05 \\
\hline III, IV & - & -17.77 & -17.81 & -17.74 & -17.69 \\
\hline III, V & - & - & -17.63 & -15.84 & -15.80 \\
\hline III, VI & - & - & - & -18.69 & -16.56 \\
\hline III, VII & - & - & - & - & -18.13 \\
\hline IV, V & - & - & -18.12 & -18.05 & -16.75 \\
\hline $\mathrm{IV}, \mathrm{VI}$ & - & - & - & -17.70 & -16.53 \\
\hline IV, VII & - & - & - & - & -18.78 \\
\hline $\mathrm{V}, \mathrm{VI}$ & - & - & - & -18.33 & -18.55 \\
\hline V, VII & - & - & - & - & -16.50 \\
\hline VI, VII & - & - & - & - & -17.36 \\
\hline
\end{tabular}


Table 3

Pairwise interaction energies $\left(\mathrm{kcal} \mathrm{mol}^{-1}\right)$ of the trimer, tetramer, pentamer, hexamer and heptamer for hydrated sulfur dioxide clusters

\begin{tabular}{|lllllll|}
\hline Pair & Dimer & Trimer & Tetramer & Pentamer & Hexamer & Heptamer \\
\hline I, II & -3.94 & -2.83 & -2.21 & -2.90 & -1.08 & -1.82 \\
\hline I, III & -5.55 & -5.02 & -2.75 & -2.07 & -2.79 & -2.04 \\
\hline I, IV & - & -2.32 & -4.27 & -2.11 & -2.32 & -2.61 \\
\hline I, V & - & - & -2.19 & -5.72 & -5.40 & -2.69 \\
\hline I,VI & - & - & - & -4.52 & -4.38 & -5.26 \\
\hline I, VII & - & - & - & - & -0.67 & -4.25 \\
\hline I, VIII & - & - & - & - & - & 0.24 \\
\hline II, III & -18.02 & -17.84 & -15.53 & -15.46 & -15.53 & -17.37 \\
\hline II, IV & - & -17.13 & -17.35 & -15.99 & -16.87 & -15.59 \\
\hline II, V & - & - & -17.17 & -16.63 & -17.57 & -17.39 \\
\hline II, VI & - & - & - & -18.27 & -18.09 & -18.91 \\
\hline II, VII & - & - & - & - & -18.36 & -15.97 \\
\hline II, VIII & - & - & - & - & - & -15.73 \\
\hline III, IV & - & -18.64 & -17.64 & -17.08 & -15.37 & -17.49 \\
\hline III, V & - & - & -16.85 & -18.09 & -17.06 & -15.37 \\
\hline III, VI & - & - & - & -15.82 & -18.33 & -17.49 \\
\hline III, VII & - & - & - & - & -15.39 & -18.06 \\
\hline III, VIII & - & - & - & - & - & -15.61 \\
\hline IV, V & - & - & -18.44 & -18.45 & -16.14 & -16.45 \\
\hline IV, VI & - & - & - & -15.87 & -16.05 & -16.33 \\
\hline IV, VII & - & - & - & - & -17.92 & -18.09 \\
\hline IV, VIII & - & - & - & - & - & -18.42 \\
\hline V, VI & - & - & - & -16.32 & -16.28 & -17.56 \\
\hline V, VII & - & - & - & - & -17.88 & -15.84 \\
\hline V, VIII & - & - & - & - & - & -19.22 \\
\hline VI, VII & - & - & - & - & -15.57 & -15.94 \\
\hline VIII & - & - & - & - & - & -15.20 \\
\hline
\end{tabular}




\begin{tabular}{|lllllll|}
\hline Pair & Dimer & Trimer & Tetramer & Pentamer & Hexamer & Heptamer \\
\hline VII, VIII & - & - & - & - & - & -15.44 \\
\hline
\end{tabular}

Table 4

The summation of QTAIM parameters corresponding to intermolecular bonding between the SO2 molecules and water and $\mathrm{SO} 2$ molecules.

\begin{tabular}{|lllllllll|}
\hline$n$ & $\Sigma \rho(r)$ & $\Sigma \nabla^{2} \rho(r)$ & $\Sigma \lambda_{1}$ & $\Sigma \lambda_{2}$ & $\Sigma \lambda_{3}$ & $\Sigma V(r)$ & $\Sigma G(r)$ & $\Sigma H(r)$ \\
\hline$\left(\mathrm{SO}_{2}\right) n$ & & & & & & & \\
\hline 2 & 0.005801 & 0.024560 & -0.00284 & -0.00094 & 0.028335 & -0.00320 & 0.004671 & 0.001470 \\
\hline 3 & 0.037336 & 0.142938 & -0.02775 & -0.02584 & 0.196520 & -0.02228 & 0.029006 & 0.006730 \\
\hline 4 & 0.070984 & 0.284806 & -0.05323 & -0.04332 & 0.381350 & -0.04253 & 0.056865 & 0.014340 \\
\hline 5 & 0.079889 & 0.321754 & -0.05929 & -0.04624 & 0.427283 & -0.04650 & 0.063467 & 0.016970 \\
\hline 6 & 0.108563 & 0.444075 & -0.07704 & -0.05043 & 0.571547 & -0.06118 & 0.086101 & 0.024920 \\
\hline 7 & 0.168147 & 0.670360 & -0.12468 & -0.09915 & 0.894189 & -0.09544 & 0.131515 & 0.036080 \\
\hline$\left(\mathrm{SO} \mathrm{O}_{2}\right) n-\mathrm{H}_{2} \mathrm{O}$ & & & & & & & \\
\hline 1 & 0.021179 & 0.065943 & -0.018941 & -0.018082 & 0.102966 & -0.014198 & 0.015342 & 0.001144 \\
\hline 2 & 0.047099 & 0.158607 & -0.042776 & -0.038174 & 0.239558 & -0.030624 & 0.035138 & 0.004514 \\
\hline 3 & 0.089639 & 0.320626 & -0.089272 & -0.079022 & 0.488922 & -0.058731 & 0.069443 & 0.010713 \\
\hline 4 & 0.124010 & 0.444185 & -0.126779 & -0.113284 & 0.684248 & -0.082626 & 0.096837 & 0.014210 \\
\hline 5 & 0.138661 & 0.538339 & -0.126911 & -0.109121 & 0.774373 & -0.088226 & 0.111405 & 0.023177 \\
\hline 6 & 0.165726 & 0.650145 & -0.154341 & -0.132530 & 0.937017 & -0.107058 & 0.134796 & 0.027739 \\
\hline
\end{tabular}

In the hydrated $\left(\mathrm{SO}_{2}\right)_{2}-\mathrm{H}_{2} \mathrm{O}$ hetrodimer cluster the highest interaction is observed for the pair (II, III), the interaction between the sulfur dioxides. The H-bonding interaction between the pair (I, II) has the least interaction energy, while the interaction between water and sulfur dioxide (I, III) has interaction energy higher than the $\mathrm{H}$-bonding dimer but far less than the sulfur dioxide dimer interaction. A similar scenario has been seen in the other larger clusters, wherein the hydrogen bonding has lower interaction energy and the intermolecular sulfur dioxide have higher interaction energies. In the case of hetroheptamer clusters, we observe a destabilization interaction between the water and the $\mathrm{SO}_{2}$ which well away from it. The highest interaction energy is observed in the case of $\mathrm{SO}_{2}$ which is in bonding with water and $\mathrm{SO}_{2}$ which is nonbonding with water. It is worth point out that the pair-wise interaction energy is higher for the H-bonding dimers in the DMSO cluster $[43,44]$. Moreover, the interaction energy decreases with the increase in distance between the water and the sulfur dioxide molecule. Despite the above, the total binding energy shows excellent linearly when plotted against the number of $\mathrm{SO}_{2}$ molecules, which confirms the cooperativity effect which stabilized the $\mathrm{SO}_{2}$ and hydrated $\mathrm{SO}_{2}$ clusters. 


\subsection{Nature of Intermolecular Interaction}

To understand the nature of intermolecular interactions between sulfur dioxides molecules in sulfur dioxide clusters and water and sulfur dioxide clusters in hydrated sulfur dioxides, we used quantitative molecular electrostatic potential analysis (MESP), electron density difference (EDD) atoms in molecule (AIM), noncovalent interaction - reduced density gradient (NCI-RDG) and Energy decomposition analysis. The acquired results are presented below.

\subsubsection{Molecular electrostatic potential (MEP) and Electron Density Difference (EDD) analysis}

Figure 4(a) illustrates the MEP of $\mathrm{SO}_{2}$ monomer, in which the red region of positive MEP designated as $\mathrm{V}_{s, \max }$ occurs around the sulfur atom, and the negative regions categorized as $\mathrm{V}_{s, \min }$ is around the oxygen atom. The former positive regions which lie perpendicular to the $S-O$ bond are designated as $\pi$-hole $[51,52]$. The $V_{s, \max }$ associated with the $\pi$-hole has a magnitude of $33.98 \mathrm{kcal} \mathrm{mol}^{-1}$ The MEP of $\mathrm{SO}_{2}$ dimer illustrated in Fig. 4(b), in which the sulfur atom which is at the free end has a magnitude of $36.83 \mathrm{kcal} \mathrm{mol}^{-1}$ a value closer to the pristine $\mathrm{SO}_{2}$ molecule. The $\mathrm{V}_{s, \text { max }}$ on the sulfur atom which gets adsorbed to the oxygen atoms of adjacent $\mathrm{SO}_{2}$ molecule got reduced to $29.59 \mathrm{kcal} \mathrm{mol}^{-1}$. A similar situation has been observed on all the studied $\mathrm{SO}_{2}$ clusters, in which the sulfur atoms at the terminal nearly retain their $\mathrm{V}_{s, \text { max }}$ values. The $\mathrm{V}_{s, \text { min }}$ value on $\mathrm{SO}_{2}$ was observed on the oxygen atoms with a value of $-19.85 \mathrm{kcal} \mathrm{mol}^{-1}$. As the name $\pi$-hole was misleading, in recent year's $\pi$-hole interactions are redesigned as chalcogen, pniocogen, and tetrel bond if it occurs on group 14,15 , and 16 atoms respectively $[53,54]$. Upon complex formation, the values observed on the oxygen which is in bonding with nearby sulfur atom gets reduced, while the oxygen atoms which are at the terminal have enhanced values generating an intramolecular $\mathrm{S} \cdots \mathrm{O}$ chalcogen bond between the $\mathrm{SO}_{2}$ molecules. Very recently, Esrafili and Mohammadian-Sabet observe the $\mathrm{V}_{s, \max }$ and $\mathrm{V}_{s, \min }$ values are persistent on linear clusters of (OCS) $)_{2-8}$ and (OCSe) $)_{2-8}$ [55]. The presence of $\mathrm{V}_{s, \text { max }}$ and $\mathrm{V}_{s, \text { min }}$ on the surface of the clusters helps for the additional $\mathrm{SO}_{2}$ adsorption on the surface and growth of cluster.

The MEP of hydrated sulfur dioxide clusters are shown in Fig. $4(\mathbf{g}-\mathbf{x})$. In the hydrated dimer cluster, the $\mathrm{V}_{s, \max }$ on bonding side of sulfur got vanished, while the opposite side has a magnitude of $24.91 \mathrm{kcal} \mathrm{mol}^{-1}$ much less than observed in the case of pristine $\mathrm{SO}_{2}$ cluster. This implies that if $\mathrm{SO}_{2}$ gets added to it will have lower stability. Moreover, the $\mathrm{V}_{\text {s.max }}$ on hydrogen atom was $50.02 \mathrm{kcal} \mathrm{mol}^{-1}$. Hence the addition of $\mathrm{SO}_{2}$ occurs at the site, leading to an $\mathrm{H}$-bonding. In the case of the timer $\left(\left(\mathrm{SO}_{2}\right)_{2}-\mathrm{H}_{2} \mathrm{O}\right)$ cluster, $\mathrm{V}_{s, \text { max }}$ on hydrogen atom was $37.39 \mathrm{kcal} \mathrm{mol}^{-1}$ which is larger than the $\pi$-hole value observed on the free $\mathrm{SO}_{2}$ molecule. Thus in the tetramer cluster $\left(\left(\mathrm{SO}_{2}\right)_{3}-\mathrm{H}_{2} \mathrm{O}\right)$ the $\mathrm{SO}_{2}$ prefers to be an $\mathrm{H}$-bonding state. In the larger clusters the $\mathrm{V}_{s, \max }$ on hydrogen atom is far less than the values observed on the sulfur atom $\pi$-hole and hence bonding occurs at the site leading to the chalcogen bonding. The reduction of the $\mathrm{V}_{s, \text { max }}$ on hydrogen atom upon complexation implies that electron density on oxygen atoms are polarized towards the positive hydrogen and tend to move from the oxygen atom on complexation. In the pentamer cluster, a $V_{s, m i n}$ value of $23.49 \mathrm{kcal} \mathrm{mol}^{-1}$ on the oxygen atom of water was observed. Henceforth in the octamer cluster, we observe the presence of two intermolecular 
chalcogen bonding between two sulfur dioxide and water molecule. Thus the value of $\mathrm{V}_{s, \max }$ or $\mathrm{V}_{s, \min }$ dictates the direction of the interaction of new $\mathrm{SO}_{2}$ molecule in larger clusters.

To provide a visualization of the changes in the electron density on complexation, the electron density difference (EDD) maps [56] for the hydrated sulfur dioxide clusters have been plotted and depicted in supporting information Fig S12. Red regions indicate regions of an increase of electron density, and blue regions are associated with regions of decreased electron density. These EDD maps are obtained by subtraction of electron densities of the complex and the corresponding monomers on their complex geometries. In the case of $\mathrm{SO}_{2}$ clusters, the monomers are $\mathrm{SO}_{2}$ molecule which binds with two oxygen as unit one and other as unit two. In the case of hydrated complexes, water is considered as unit one and $\mathrm{SO}_{2}$ cluster as unit two. In the pristine $\mathrm{SO}_{2}$ clusters, the noticeable aspect is the build of blue regions encamping the regions where sulfur atom which is in $\mathrm{S} \cdots \mathrm{O}$ chalcogen bonding. In the larger clusters, these regions were found to merge generating a large surface. Also, notice that the oxygen adjacent to the sulfur atoms gains electron density envisaged by the red regions. Thus a substantial electron density shift from the sulfur (donor) to the oxygen atom (acceptor) occurs during the cluster formation. This was also observed in the hydrated sulfur dioxide clusters. Besides the above, we also notice a presence of red regions fully surrounding the water molecules in hydrated clusters. This corresponds to the gain of electron density by water molecules similar to the previously reported hydrated complexes.

\subsubsection{Atoms in molecules}

The quantum theory of atoms in molecules provides detailed information about the existence, strength, and characteristics of different intermolecular interactions in various complexes [56-59]. The presence of a bond critical point (BCP) between sulfur dioxide and sulfur dioxide/water can be used to characterize the chalcogen bonds. Molecular graphs for all the pristine $\mathrm{SO}_{2}$ cluster and hydrated $\mathrm{SO}_{2}$ clusters is depicted in Fig. 5 . The electron density properties at the BCPs for sulfur dioxide clusters are provided in Table $\mathbf{S} 1$ and for hydrated clusters in Table S2. The electron density $\rho(r)$ at the intermolecular $S \cdots 0$ in sulfoxide clusters are in the range of $0.005-0.0133$ a.u. which fall in the accepted range of chalcogen bonding $[60,61]$. However, these values are much smaller than observed in hydrogen bonds (0.002-0.035 a.u.), which indicates that these interactions are weak. The Laplacian of electron density were all positive values in the range $0.019-0.052$ a.u. and are closed-shell weak interactions. The ratio of kinetic and potential energy density at $B C P,-G(r) / V(r)$ is greater than unity at all the BCPs revealing the presence of noncovalent interactions. Ellipticity is a measure of delocalization of electron and thus the bond stability or weakness of the bond. A high ellipticity value indicates the instability of the bond [62]. As a general trend the ellipticity values of some chalcogen bonds in dimer sulfoxide clusters increases with the cluster size indicating that those bonds are less stable. In the hydrated complexes, the observed at the BCPs between water and sulfur dioxides have $\rho(r)$ values in the range 0.005-0.018 a.u. which closer to the values suggested by Koch and Popelier for H-bonding's [63]. Based on the values at BCPs with hydrogen bonding $\nabla^{2} \rho(r)$ and $H(r)>0$ and hence can be classified as weak and electrostatic dominant. From Table S1, it is evident that $\rho(r)$ values for the chalcogen bonds are in the range of 0.004-0.033 au. which are higher than the H-bond values observed in the same complexes, however $\nabla^{2} \rho(r)$ and $H(r)>0$ and hence can be classified as weak and electrostatic dominant. The Laplacian at all BCPs are positive and the ration $-G(r) / V(r)$ values for most of the BCPs are greater than unity revealing the presence of 
noncovalent nature. The intermolecular interaction energy computed using the Espinosa method is in the range of $-0.99--4.38 \mathrm{kcal} \mathrm{mol}^{-1}$. The above values in the acceptable range of previously reported weakly $\mathrm{H}-$ bonding systems $[64,65]$. The computed summation of electron density properties at the BCPs is provided in Table 3. The results indicate that the summation of $\rho(r)$ and $\nabla^{2} \rho(r)$ values of clusters increases with the size of the cluster and is always higher than that of dimers. Recently, Esrafili et al observed that the average $\rho(r)$ and $\nabla^{2} \rho(r)$ values of larger clusters of OCS and OCSe are greater than those of dimers and associated it with the existence of chalcogen bond cooperativity due to the redistribution of electronic density in the clusters [55]. In our present study, we observe a very $\rho(r)$ and $\nabla^{2} \rho(r)$ value for the BCPs with $\mathrm{H}$-bonding, while the other sulfur dioxide part of hydrated clusters were found to have higher low $\rho(r)$ and $\nabla^{2} \rho(r)$ compared to the pristine sulfur dioxide clusters. Thus, the presence of $\mathrm{H}$-bond and chalcogen bond act cooperatively which resulted in the redistribution of electronic density in the hydrated clusters.

\subsubsection{EDA analysis}

Decomposition of the total interaction energy into repulsive and attractive terms opens a window to know the nature of the interaction. In Table 5, we provide the energy decomposition analysis results for the hydrated system obtained using the Morokuma's bond energy decomposition method [66]. In the Morokuma's method the attractive terms are partitioned into electrostatic, orbital, dispersion energies. It can be seen from Table 5, the destabilization Pauli's terms increase with the cluster size and are highest for the pentamer cluster $\left(\mathrm{SO}_{2}\right)_{4}-\mathrm{H}_{2} \mathrm{O}$, presumable due to the addition of one more sulfur dioxide molecule to the tetramer which exists in a tetrahedral geometry. In attractive terms, the dominant is the electrostatic attraction which accounts for $60 \%$. In the hydrated complexes, the highest electrostatic forces are observed in the case of the dimer $\mathrm{SO}_{2}-$ $\mathrm{H}_{2} \mathrm{O}$ complex which doesn't have an intermolecular hydrogen bonding. In all the complexes with the increase in the number of $\mathrm{H}$-bonding, electrostatic attraction decreases. The orbital contribution, which corresponds to 29.12 to $37.80 \%$ of the total attractive terms, increases with the increase in the number of intermolecular $\mathrm{H}-$ bonds. Among the attractive interactions, the weakest was the dispersion term and is least for tetramer $\left(\mathrm{SO}_{2}\right)_{3}-\mathrm{H}_{2} \mathrm{O}$ complex and highest for the octamer complex $\left(\mathrm{SO}_{2}\right)_{7}-\mathrm{H}_{2} \mathrm{O}$. Overall the electrostatic interaction is dominated in complexes with more intermolecular chalcogen bonding and orbital interaction is higher for systems with more intermolecular $\mathrm{H}$-bonding. 
Table 5

Energy decomposition analysis for the hydrated sulfur dioxide clusters at the B3LYP-D3/TZ2P level on the PW6B95-D3/Def2TZVP optimized geometry.

The percentage of contribution of the electrostatic interaction to the total attractive interactions is given in parenthesis.

\begin{tabular}{|lllll|}
\hline & $\Delta \mathrm{E}_{\text {Pauli }}$ & $\Delta \mathrm{E}_{\text {elstat }}$ & $\Delta \mathrm{E}_{\text {orb }}$ & $\Delta \mathrm{E}_{\text {disp }}$ \\
\hline $\mathrm{SO}_{2}-\mathrm{H} 2 \mathrm{O}$ & 11.95 & $-10.49(62.22)$ & $-4.91(29.12)$ & $-1.46(8.66)$ \\
$\left(\mathrm{SO}_{2}\right)_{2}-\mathrm{H} 2 \mathrm{O}$ & 20.34 & $-17.90(59.13)$ & $-8.97(29.63)$ & $-3.40(11.23)$ \\
$\left(\mathrm{SO}_{2}\right)_{3}-\mathrm{H} 2 \mathrm{O}$ & 29.45 & $-24.03(56.61)$ & $-14.94(35.19)$ & $-3.48(8.20)$ \\
$\left(\mathrm{SO}_{2}\right)_{4}-\mathrm{H} 2 \mathrm{O}$ & 40.38 & $-31.16(54.66)$ & $-21.55(37.80)$ & $-4.30(7.54)$ \\
$\left(\mathrm{SO}_{2}\right)_{5}-\mathrm{H} 2 \mathrm{O}$ & 33.13 & $-30.95(58.57)$ & $-16.26(30.77)$ & $-5.63(10.65)$ \\
$\left(\mathrm{SO}_{2}\right)_{6}-\mathrm{H} 2 \mathrm{O}$ & 35.31 & $-31.99(58.02)$ & $-17.85(32.37)$ & $-5.30(9.61)$ \\
$\left(\mathrm{SO}_{2}\right)_{7}-\mathrm{H} 20$ & 36.98 & $-32.75(56.99)$ & $-17.75(30.89)$ & $-6.97(12.13)$ \\
\hline
\end{tabular}

\subsubsection{Non-covalent interactions-Reduced density gradient analysis}

To visualize the noncovalent interactions, including weak van der Waals interaction, hydrogen bonding, and steric repulsion $\mathrm{NCl-RDG}$ analysis were carried out on the sulfur dioxide and hydrated sulfur dioxide clusters $[68,69]$. The 2D NCl graphs with inserted RDG isosurfaces for the sulfur dioxide and hydrated sulfur dioxide clusters are provided in Fig. 6 and supporting information in Fig. S13. In the NCl graphs, low density and low gradient spikes that appear on the negative $\lambda_{2}(r)$ values are for attractive interactions (specifically electrostatic/hydrogen bonding) and positive values are for the repulsive interactions. For the $\mathrm{SO}_{2} \mathrm{molecule}_{\text {, }}$ the $\mathrm{NCl}$ graphs is shown in Fig. 6(a), spikes are not visible due to the absence of attractive and repulsive forces. In the dimer $\left(\mathrm{SO}_{2}\right)_{2}$ clusters, there were spikes at $\operatorname{sign}\left(\lambda_{2}\right) \rho=-0.006 \mathrm{X}$ and $0.006 \mathrm{X}$ a.u. appeared due to the attractive chalcogen bonding and sulfur-sulfur repulsive forces respectively. These interactions are evident from the RDG isosurfaces shown at the right top of Fig. 6(b) with green and yellowish-brown patches. In the trimer $\left(\mathrm{SO}_{2}\right)_{3}$ cluster, we also notice the appearance of a pale green patch surrounded by a yellowishbrown patch between the oxygen-oxygen atoms. Their corresponding spikes were also noticed in the $\mathrm{NCl}$ graph. Interestingly, the presence of such interaction is not visible in the AIM analysis. The number of $\mathrm{S} \cdots \mathrm{O}$ bonds increases with the increases in cluster size; thus the number of spikes in the attractive regions also got increased with the cluster size. The negative $\lambda_{2}(r)$ values are very close and in the range -0.006 to -0.015 a.u. In the cluster sizes above $n>5$, the spikes got merged and hence not visible as distinctly for each of the chalcogen bonding.

In the hydrated sulfur dioxide cluster $\mathrm{SO}_{2}-\mathrm{H}_{2} \mathrm{O}$, we notice the presence of a spike at -0.02 a.u. and a broad spike in the region 0.018 a.u. The corresponding RDG isosurfaces show the presence of a blue patch indicating the presence of a strong electrostatic component between the water and $\mathrm{SO}_{2}$ molecule. Besides, a red patch at the edges of the blue patch is also noticed which is due to the repulsive forces between them. In 
the trimer cluster $\left(\mathrm{SO}_{2}\right)_{2}-\mathrm{H}_{2} \mathrm{O}$, the $\mathrm{S} \cdots \mathrm{O}$ chalcogen bond between a water molecule and $\mathrm{SO}_{2}$ molecules appears in the more negative region at -0.028 a.u. and green spikes due to intermolecular chalcogen bonding between the $\mathrm{SO}_{2}$ appears between 0.010-0.015 a.u. It is worth point out the intermolecular chalcogen regions are observed in the range -0.006 to -0.015 a.u for the pristine $\mathrm{SO}_{2}$ clusters. In the tetramer and pentamer clusters, the blue spikes are shifted to more negative regions along with the increase in the number of green spikes. In the larger clusters, the spike due to the intermolecular chalcogen bonding between water and $\mathrm{SO}_{2}$ molecules gets splattered, indicating the intermolecular $\mathrm{SO}_{2}$ chalcogen bonding's cooperatively act to enhances the increased interaction between the water and $\mathrm{SO}_{2}$ molecule. These results are in good agreement with the geometry, pairwise energetic, MESP, AIM, and EDA analysis.

\section{Conclusion}

In conclusion, the pristine $\mathrm{SO}_{2}$ and binary intermolecular clusters formed by $\mathrm{SO}_{2}$ molecules and water was investigated using density functional theory and wave functional methods. The putative global minimum of $\mathrm{SO}_{2}$ molecules have 3D growth pattern with tetrahedral configurations and several closely positioning isomers were observed. In the hydrated $\mathrm{SO}_{2}$ clusters, the structures with chalcogen bonding alone or with only hydrogen bonding are less stable than structures with both bonding. The total binding energy of the $\mathrm{SO}_{2}$ and hydrated $\mathrm{SO}_{2}$ clusters increases with the increase in the number of $\mathrm{SO}_{2}$ molecules. For the pristine $\mathrm{SO}_{2}$ clusters, incremental binding energy decreases with the increase in cluster size and nears the saturation limit. The cluster adsorption energy for $\mathrm{SO}_{2}$ clusters on water increase with the sulfur dioxide cluster size and reaches a near saturation. Relatively less binding energy and incremental binding energy of hydrated $\mathrm{SO}_{2}$ clusters intend that they are less stable/highly reactive compared to pristine $\mathrm{SO}_{2}$ clusters. The pristine $\mathrm{SO}_{2}$ and the hydrated $\mathrm{SO}_{2}$ cluster show cooperativity effects which are evident from the excellent linearity plot of binding energy/polarizability vs the number of $\mathrm{SO}_{2}$ molecules which was supported by the pairwise energies computed on the PGM clusters.

Molecular electrostatic potential (MEP) analysis show the oxygen atoms which are at the terminal have

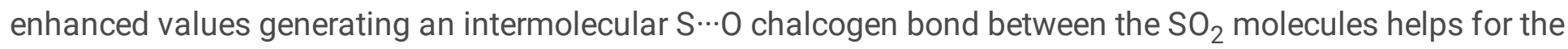
growth of clusters. MEP also explains the reason for the facile formation of S $\cdots 0$ chalcogen than hydrogen bonding in hydrated sulfur dioxide. Atoms in molecule (AIM) analysis characterize the bonds to be weak and electrostatic dominant. The observed $\rho(r)$ values at BCPs with hydrogen bonds are lower than the values observed for the $S \cdots O$ chalcogen. EDA analysis shows electrostatic interaction is dominated in complexes with more intermolecular chalcogen bonding and orbital interaction for systems with intermolecular $\mathrm{H}$-bonding. The reduced density gradient (RDG) analysis of sulfur dioxide clusters has blue patches and green patches due to $S \cdots O$ chalcogen bonding $O \cdots O$ electrostatic interaction. The RDG analysis of hydrated sulfur dioxide clusters shows intensive blue patches and green patches for the existence of $S \cdots O$ chalcogen and hydrogen bonding respectively. Thus, the presence of strong electrostatic $\mathrm{S} \cdots \mathrm{O}$ chalcogen interaction and weak $\mathrm{H}$ bonds acts cooperatively and stabilize the hydrated sulfur dioxide clusters.

\section{Declarations}




\section{Funding}

This work carried out did not receive any specific grant from funding agencies in the public, commercial, and/or not-for-profit sectors.

\section{Conflicts of Interest/Competing interests}

The author declares no conflict/competing of interest

\section{Availability of data and material}

The datasets generated during and/or analysed during the current study are available from the author on reasonable request.

\section{Code availability}

Not applicable.

\section{Authors contributions}

Not applicable.

\section{Acknowledgment}

The author thanks the staff of the Center for Computational Materials Science, Institute for Materials Research, Tohoku University, and the supercomputer resources through the HPCI System Research Project (Project ID: hphp200040).

\section{References}

1. Bauduin S, Clarisse L, Clerbaux C, Hurtmans D, Coheur P-F (2014) IASI observations of sulfur dioxide (SO2) in the boundary layer of Norilsk. J Geophys Res 119:4253-4263

2. Theys N, Campion R, Clarisse L, Brenot H, van Gent J, Dils B, Corradini S, Merucci L, Coheur P-F, Van Roozendael M, Hurtmans D, Clerbaux C, Tait S, Ferrucci $F(2013)$ Valconic $\mathrm{SO}_{2}$ fluxes derived from satellite data: a survey using OMI, GOME-2, IASI and MODIS. Atoms Chem Phys 13:5945:5968

3. Solomon S, Qin D, Manning M, Chen Z, Marquis M, Averyt KB, Tignor M, Miller HL (2007) Eds. Contribution of Working Group I to the Fourth Assessment Report of the Intergovernmental Panel on Climate Change. Cambridge University Press, Cambridge

4. Kurten T, Lane JR, Jørgensen S, Kjaergaard HG (2011) A computational study of the oxidation of $\mathrm{SO}_{2}$ to $\mathrm{SO}_{3}$ by gas-phase organic oxidants. J Phys Chem A 115:8669-8681

5. Gimeno-Prat A, Cortes-Sanchon A, Martin A, Baya M, Casas JM (2018) Platinum-mediated monohydration of $\mathrm{SO}_{2}$. Dalton Trans 47:16846-16850 
6. Loerting T, Kroemer RT, Liedel KR (2000) On the competing hydrations of sulphur dioxide and sulphur trioxide in our atmosphere. Chem Commun 999-1000

7. Shamay ES, Valley NA, Moore FG, Richmond GL (2013) Staying hydrated: the molecular journey of gaseous sulfur dioxide to a water surface. Phys Chem Chem Phys 15:6893-6903

8. Pehkonen S, Lundell J, Khriachtchev L, Pettersson M, Rasanen M (2004) Matrix isolation and quantum chemical studies on the $\mathrm{H}_{2} \mathrm{O}-\mathrm{SO}_{2}$ complex. Phys Chem Chem Phys 6:4607-4613

9. Jana I, Naskar S, Das M, Nandi D (2019) Probing the molecular structure and properties of neutral and anionic ground states of $\mathrm{SO}_{2}$ and $\mathrm{CO}_{2}$. Eur Phys J D 73:233

10. Taleb-Bendiab A, Hilling IIKW, Kuczkowski RL (1991) The microwave spectrum, structure and tunnelling motion of the sulfur dioxide dimer. J Chem Phys 94:6956

11. Ito $\mathrm{F}$ (2007) Gas phase infrared spectra of $\mathrm{SO}_{2}$ clusters and quantum chemical calculations of some stable isomer. Chem Phys Chem 436:335-340

12. Ito $\mathrm{F}$, Hirabayashi S (2009) Infrared spectroscopy of $\mathrm{SO}_{2}$ clusters in rare gas matrices revisited: assignment of species in Ar matrix. Chem Phys 358:209-218

13. Dong F, Heinbuch S, Rocca JJ (2006) Single photon ionization of van der Waals clusters with a soft x-ray laser: $\left(\mathrm{SO}_{2}\right) \mathrm{n}$ and $\left(\mathrm{SO}_{2}\right) \mathrm{n}\left(\mathrm{H}_{2} \mathrm{O}\right) \mathrm{m}$. J Chem Phys 125:154317

14. Davis AR, Chatterjee RM (1975) A vibrational-spectroscopic study of the $\mathrm{SO}_{2}-\mathrm{H}_{2} \mathrm{O}$ system. J Solution Chem 4:399-412

15. Risberg ED, Eriksson L, Mink J, Pettersson LGM, Skripkin MY, Sandstrom M (2007) Sulfur X-ray absorption and vibrational spectroscopic study of sulfur dioxide, sulfite, and sulfonate solutions and of the substituted sulfonate ions $\mathrm{X}_{3} \mathrm{CSO}_{3^{-}}(\mathrm{X}=\mathrm{H}, \mathrm{Cl}, \mathrm{F})$. Inorg Chem 46:8332-8348

16. Zhong J, Zhu C, Li L, Richmond GL, Francisco JS, Zeng XC (2017) Interaction of $\mathrm{SO}_{2}$ with the surface of a water nanodroplet. J Am Chem Soc 139:17168-17174

17. Misiewicz JP, Moore KB III, Franke PR, Morgan WJ, Turney JM, Douberly GE, Schaefer HF III (2020) Sulfurous and sulfonic acids: predicting the infrared spectrum and setting the surface straight. J Chem Phys 152:024302

18. Hirabayashi S, Ito F, Yamada KMT (2006) Infrared spectra of the $\left(\mathrm{H}_{2} \mathrm{O}\right) \mathrm{n}-\mathrm{SO}_{2}$ complexes in argon matrices. J Chem Phys 125:034508

19. Cukras J, Sadlej J (2007) Structure and energetics of weakly bound water-sulfur dioxide complexes. J Mol Struct (THEOCHEM) 819:41-51

20. Steudel R, Steudel Y (2009) Sulfur dioxide and water: structures and energies of the hydrated species $\mathrm{SO}_{2} \cdot \mathrm{nH}_{2} \mathrm{O},\left[\mathrm{HSO}_{3}\right]^{-} \cdot \mathrm{nH}_{2} \mathrm{O},\left[\mathrm{SO}_{3} \mathrm{H}\right]^{-} \cdot \mathrm{nH}_{2} \mathrm{O}$ and $\mathrm{H}_{2} \mathrm{SO}_{3} \cdot \mathrm{nH}_{2} \mathrm{O}(\mathrm{n}=0-8)$. Eur J Inorg Chem 1393-1405

21. Azofra LM, Scheiner S (2014) Complexes containing $\mathrm{CO}_{2}$ and $\mathrm{SO}_{2}$. Mixed dimers, trimmers and tetramers. Phys Chem Chem Phys 16:5142-5149

22. Azofra LM, Scheiner S (2014) Complexation of $n . S_{2}$ molecules ( $\left.n=1,2,3\right)$ with formaldehyde and thioformaldehyde. J Chem Phys 140:034302

23. Azofra LM, Scheiner S (2014) Strongly bound noncovalent $\left(\mathrm{SO}_{3}\right) \mathrm{n}: \mathrm{H}_{2} \mathrm{CO}$ complexes $(\mathrm{n}=1,2)$. Phys Chem Chem Phys 16:18974 
24. Jin Y, Saragi RT, Juanes M, Feng G, Lessarri A (2021) Interaction topologies of the S ...O chalcogen bond: the conformational equilibrium of the cyclohexanol $\cdots \mathrm{SO}_{2}$. cluster Phys Chem Chem Phys 23:1079910806

25. Fick RJ, Kroner GM, Nepal B, Magnani R, Horowitz S, Houtz RL, Trievel RC (2015) Sulfur-oxygen chalcogen bonding mediates AdoMet recognition in the lysine methyltransferase SET7/9. ACS Chem Biol $11: 748-754$

26. Adhikari U, Scheiner S (2014) Effects of Charge and Substituent on the S $\cdots \mathrm{N}$ Chalcogen Bond. J Phys Chem A 118:3183-3192

27. Zierkiewicz W, Fanfrlik J, Hobza P, Michalska D, Zeeger-Huyskens T (2016) Ab initio and DFT studies of the interaction between carbonyl and thiocarbonyl groups: the role of $\mathrm{S} \cdots \mathrm{O}$ chalcogen bonds. Theor Chem Acc 135:217

28. Esrafili MD, Vakili M, Solimannejad M (2014) Cooperative interaction between $\pi$-hole and single electron o-hole interactions in $\mathrm{O}_{2} \mathrm{~S} \cdots \mathrm{NCS} \cdots \mathrm{CH}_{3}$ and $\mathrm{O}_{2} \mathrm{Se} \cdots \mathrm{NCX} \cdots \mathrm{CH}_{3}$ complexes $(\mathrm{X}=\mathrm{F}, \mathrm{Cl}, \mathrm{Br}$ and $\mathrm{I})$. Mol Phys 112:2078-2084

29. Esrafili MD, Vakili M (2014) Halogen bonds enhanced by $\sigma$-hole and $\pi$-hole interactions: a comparative study on cooperativity and competition effects between $\mathrm{X} \bullet \bullet \mathrm{N}$ and $\mathrm{S} \bullet \bullet \mathrm{N}$ interactions in $\mathrm{H}_{3} \mathrm{~N} \bullet \bullet X \mathrm{XN} \bullet \bullet \mathrm{SF}_{2}$ and $\mathrm{H}_{3} \mathrm{~N} \bullet \bullet X C N \bullet \bullet \mathrm{SO}_{2}$ complexes $(\mathrm{X}=\mathrm{F}, \mathrm{Cl}, \mathrm{Br}$ and $\mathrm{I})$. J Mol Model 20:2291

30. Previtali V, Sanchez-Sanz G, Trujillo C (2019) Theoretical investigation of cyano-chalcogen dimers and their importance in molecular recognition. Chem Phys Chem 20:3186-3194

31. Zhang J, Dolg M (2015) ABCluster: The artificial bee colony algorithm for cluster global optimization. Phys Chem Chem Phys 17:24173-24181

32. Zhang J, Dolg M (2016) Global optimization of rigid molecular clusters by the artificial bee colony algorithm. Phys Chem Chem Phys 18:3003-3010

33. Tasinato N, Grimme S (2015) Unveiling the non-covalent interactions of molecular homodimers by dispersion-corrected DFT calculations and collision-induced broadening of ro-vibrational transitions: application to $\left(\mathrm{CH}_{2} \mathrm{~F}_{2}\right)_{2}$ and $\left(\mathrm{SO}_{2}\right)_{2}$. Phys Chem Chem Phys 17:5659-5669

34. Malloum A, Conradie J (2020) Global and local minima of protonated acetonitrile clusters. New J Chem 44:17558-17569

35. Simon S, Duran M, Dannenberg JJ (1996) How does basis set superposition error change the potential surfaces for hydrogen bonded dimers? J Chem Phys 105:11024-11031

36. Frisch MJ, Trucks GW, Schlegel HB, Scuseria GE, Robb MA, Cheeseman JR, Scalmani G, Barone V, Petersson GA, Nakatsuji H, Li X, Caricato M, Marenich AV, Bloino J, Janesko BG, Gomperts R, Mennucci B, Hratchian HP, Ortiz JV, Izmaylov AF, Sonnenberg JL, Williams-Young D, Ding F, Lipparini F, Egidi F, Goings J, Peng B, Petrone A, Henderson T, Ranasinghe D, Zakrzewski VG, Gao J, Rega N, Zheng G, Liang W, Hada M, Ehara M, Toyota K, Fukuda R, Hasegawa J, Ishida M, Nakajima T. Honda Y, Kitao O, Nakai H, Vreven T, Throssell K, Montgomery JA Jr, Peralta JE, Ogliaro F, Bearpark MJ, Heyd JJ, Brothers EN, Kudin KN, Staroverov VN, Keith TA, Kobayashi R, Normand J, Raghavachari K, Rendell AP, Burant JC, lyengar SS, Tomasi J, Cossi M, Millam JM, Klene M, Adamo C, Cammi R, Ochterski JW, Martin RL, Morokuma K, Farkas O, Foresman JB, Fox DJ (2019) Gaussian 16, Revision C.01, Gaussian, Inc., Wallingford 
37. Bulat FA, Toro-Labbé A, Brinck T, Murray JS, Politzer P (2010) Quantitative analysis of molecular surfaces: Volumes, electrostatic potentials and average local ionization energies. J Mol Model 16:1679-1691

38. Lu T, Chen F (2012) Multiwfn: A multifunctional wavefunction analyser. J Comput Chem 33:580-592

39. Chemcraft - graphical software for visualization of quantum chemistry computations. https://www.chemcraftprog.com

40. AIMAll (Version 19.10.12), Keith, TA (2019) TK Gristmill Software, Overland Park KS, USA, (aim.tkgristmill.com)

41. Ito $\mathrm{F}$, Hirabayashi S (2009) Infrared spectroscopy of $\mathrm{SO}_{2}$ clusters in rare gas matrices revisited: assignment of species in Ar matrix. Chem Phys 358:209-218

42. Ito $\mathrm{F}$ (2007) Gas phase infrared spectra of $\mathrm{SO}_{2}$ clusters and quantum chemical calculations of some stable isomers. Chem Phys Lett 436:335-340

43. Venkataramanan NS, Suvitha A, Kawazoe Y (2019) Density functional theory study on the dihydrogen bond cooperativity in the growth behavior of dimethyl sulfoxide clusters. J Mol Liq 249:454-462

44. Venkataramanan NS, Suvitha A (2018) Nature of bonding and cooperativity in linear DMSO clusters: A DFT, AIM and NCl analysis. J Mol Graph Model 81:50-59

45. Song C, Tian Z, Wang C, Shi R, Liu J (2021) Growth behaviour and properties of $(H F)_{1-16}$ clusters. Struct Chem 32:395-403

46. Remya K, Suresh CH (2014) Cooperativity and cluster growth patterns in acetonitrile: A DFT study. J Comput Chem 35:910-922

47. Alkorta I, Blanco F, Elguero J (2009) A Computational Study of the Cooperativity in Clusters of Interhalogen Derivatives. Struct Chem 20:63-71

48. Skwara B, Bartkowiak W, Zawada A, Gora RW, Leszczynski J (2007) On the cooperativity of the interaction-induced (hyper)polarizabilities of the selected hydrogen-bonded trimmers. Chem Phys Lett 436:116-123

49. Roztoczynsk A, Kozlowska J, Lipkowski P, Bartkowiak W (2014) Does the spatial confinement influence the electric properties and cooperative effects of the hydrogen bonded systems? HCN chains as a case study. Chem Phys Lett 608:264-268

50. Tebben L, Muck-Lichtenfeld C, Fernandez G, Grimme S, Studer A (2017) From additivity to cooperativity in chemistry: can cooperativity be measured. Chem Eur J 23:5864-5873

51. Jin Y, Saragi RT, Juanes M, Feng G, Lessari A (2021) Interaction topologies of the S …0 chalcogen bond: the conformational equilibrium of the cyclohexanol $\cdots \mathrm{SO}_{2}$ cluster. Phys Chem Chem Phys 23:1079910806

52. Polizter P, Murray JS, Clark T (2010) Halogen bonding: an electrostatically-driven highly directional noncovalent interaction. Phys Chem Chem Phys 12:7748-7757

53. Zhang J, Li W, Cheng J, Liu Z, Li Q (2018) Cooperative effects between $\pi$-hole triel and $\pi$-hole chalcogen bonds. RSC Adv 8:26580-26588

54. Vogel L, Wonner P, Huber SM (2019) Chalcogen bonding: an overview. Angew Chem Int Edn 58:18801891 
55. Esrafili MD, Mohammadian-Sabet F (2014) Ab initio calculations of cooperativity effects on chalcogen bonding: linear clusters of (OCS) $2-8$ and (OCSe) $2-8$. Struct Chem 26:199-206

56. Brezgunova ME, Lieffrig J, Aubert E, Dahaoui S, Fertey P, Lebergue S, Angyan JG, Fourmigue M, Espinosa E (2013) Chalcogen Bonding: Experimental and Theoretical Determinations from Electron Density Analysis. Geometrical Preferences Driven by Electrophilic - Nucleophilic Interactions. Cryst Growth Des 13:3283-3289

57. Venkataramanan NS, Suvitha A (2017) Theoretical Investigation of the Binding of Nucleobases to Cucurbiturils by Dispersion Corrected DFT Approaches. J Phys Chem B 121:4733-4744

58. Venkataramanan NS (2016) Cooperativity of intermolecular hydrogen bonds in microsolvated DMSO and DMF clusters: a DFT, AIM, and NCI analysis. J Mol Model 22:151

59. Venkataramanan NS, Suvitha A (2015) Encapsulation of sulfur, oxygen, and nitrogen mustards by cucurbiturils: a DFT study. J Incl Phenom Macrocyclic Chem 83:387-400

60. Esrafili MD, Nurazar R (2016) Chalcogen bonds formed through $\pi$-holes: $\mathrm{SO}_{3}$ complexes with nitrogen and phosphorus bases. Mole Phys 114:276-282

61. Azofra LM, Alkorta I, Schieine S (2015) Chalcogen Bonds in Complexes of SOXY (X, Y = F, Cl) with Nitrogen Bases. J Phys Chem A 119:535-541

62. Louit G, Hocquet A, Ghomi M (2002) Intramolecular hydrogen bonding in ribonucleosides: an AIM topological study of the electronic density. Phys Chem Chem Phys 4:3843-3848

63. Koch U, Popelier PLA (1995) Characterization of C-H-O hydrogen bonds on the basis of the charge density. J Phys Chem 99:9747-9754

64. Grabowski SJ (2021) Intramolecular Hydrogen Bond Energy and Its Decomposition-O-H $\cdots$ O Interactions, Crystals. 11: 5

65. Rusinska-Roszak D (2017) Energy of intramolecular hydrogen bonding in ortho-hydroxybenzaldehydes, phenones and quinones. Transfer of aromaticity from ipso-benzene ring to the enol system(s), molecules. 22:481-501

66. Morokuma K (1971) Molecular Orbital Studies of Hydrogen Bonds. III. $\mathrm{C}=\mathrm{O} \cdots \mathrm{H}-\mathrm{O}$ Hydrogen Bond in $\mathrm{H}_{2} \mathrm{CO} \cdots \mathrm{H}_{2} \mathrm{O}$ and $\mathrm{H}_{2} \mathrm{CO} \cdots 2 \mathrm{H}_{2} \mathrm{O}$. J Chem Phys 55:1236

67. Varadwaj PR, Varadwaj A, Marques HM, MacDougall PJ (2019) The chalcogen bond: Con it be formed by oxygen? Phys Chem Chem Phys 21:19969-19986

68. Varadwaj PR (2019) Does oxygen feature chalcogen bonding. Molecules 24:3166

\section{Figures}



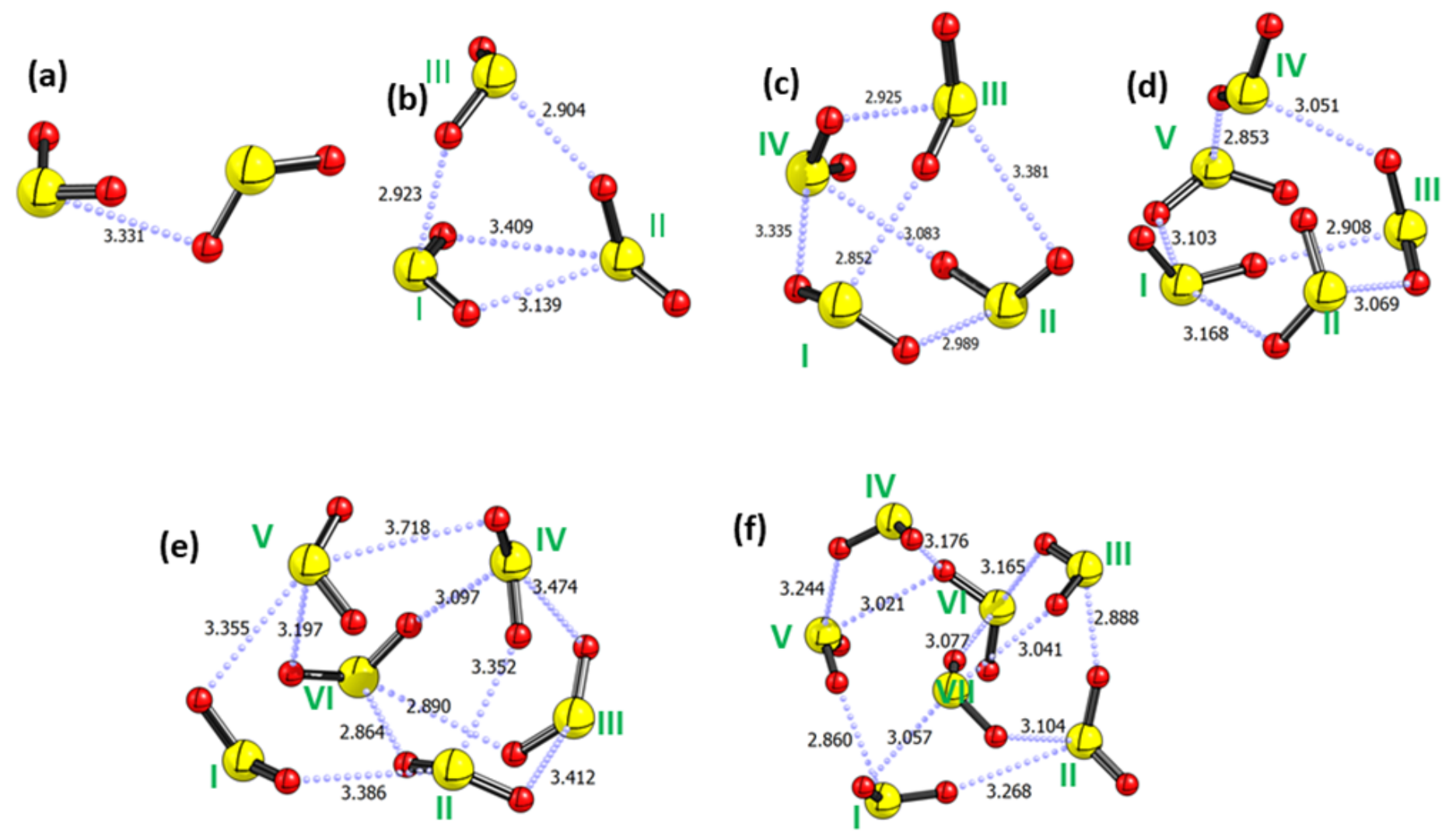

\section{Figure 1}

Optimized geometries of PGM sulfur dioxide clusters (a) monomer (b) dimer (c) trimer (e) tetramer (f) pentamer (g) hexamer (h) heptamer. Distances are in $\AA$ 

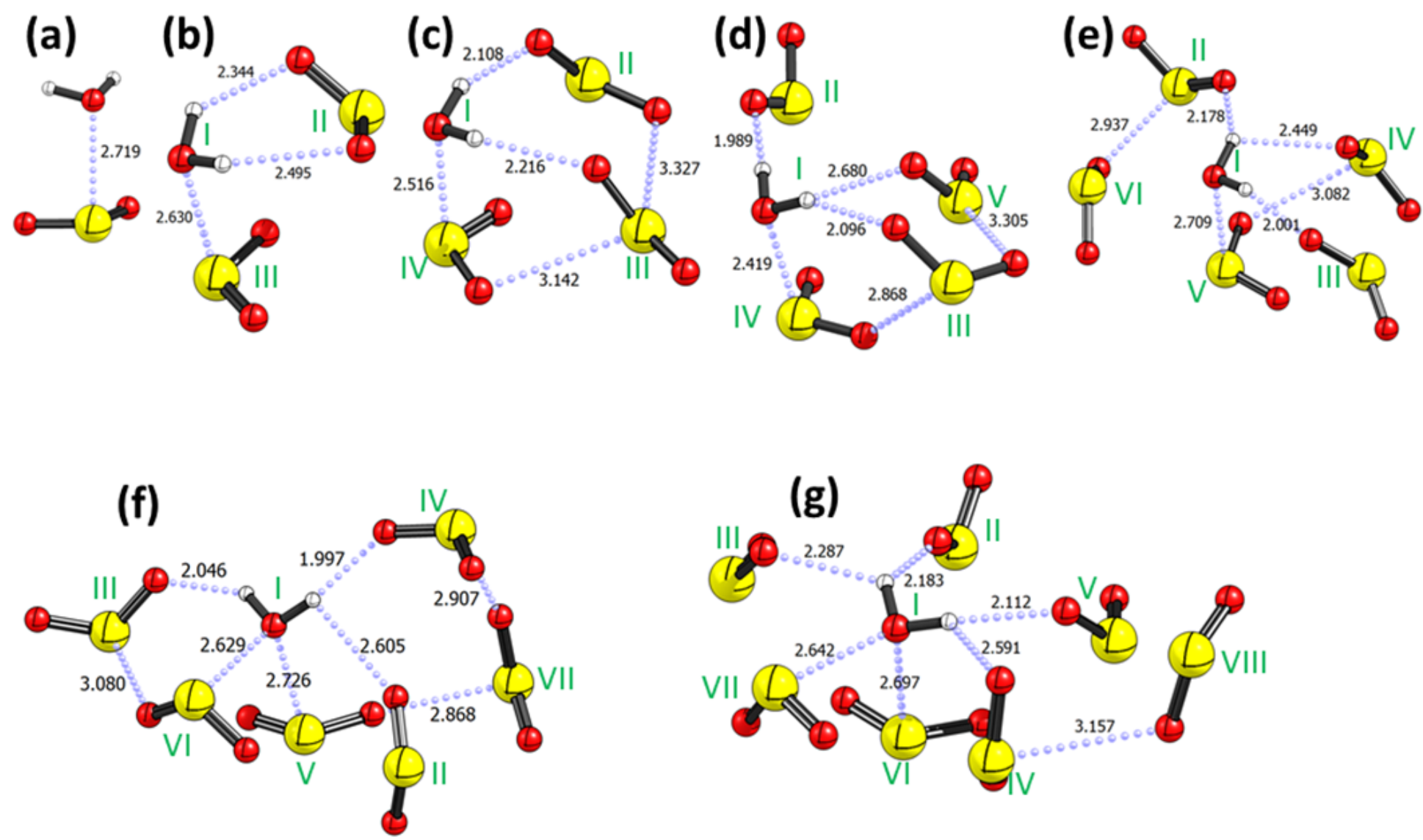

\section{Figure 2}

Optimized geometries of PGM hydrated sulfur dioxide clusters (a) hetrodimer (b) hetrotrimer (c) hetrotetramer (d) hetropentamer (e) hetrohexamer (f) hetroheptamer. Distances are in $\AA$ 
(a)

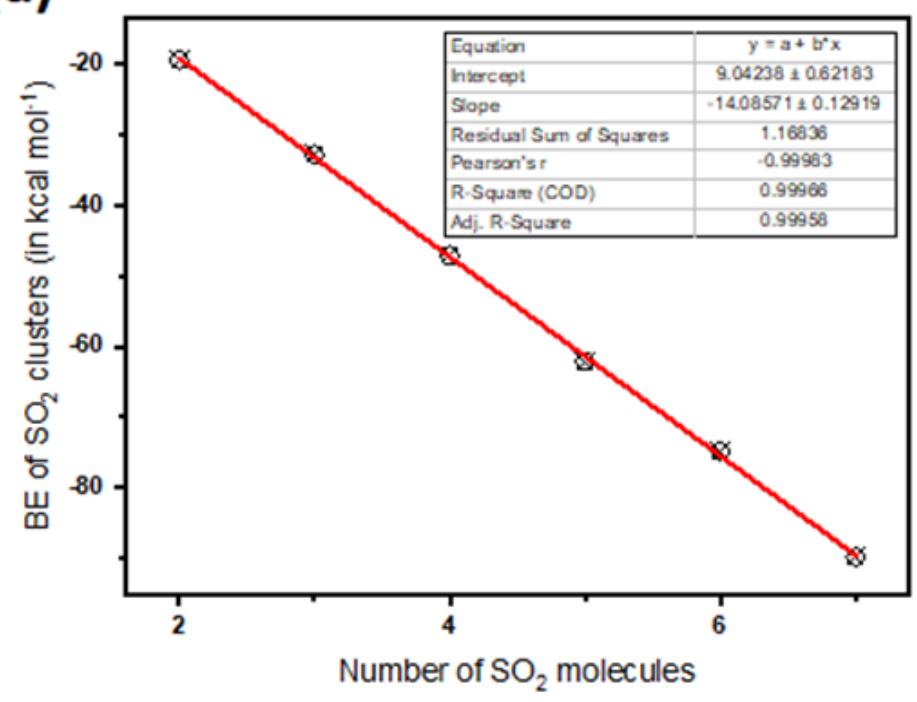

(c)

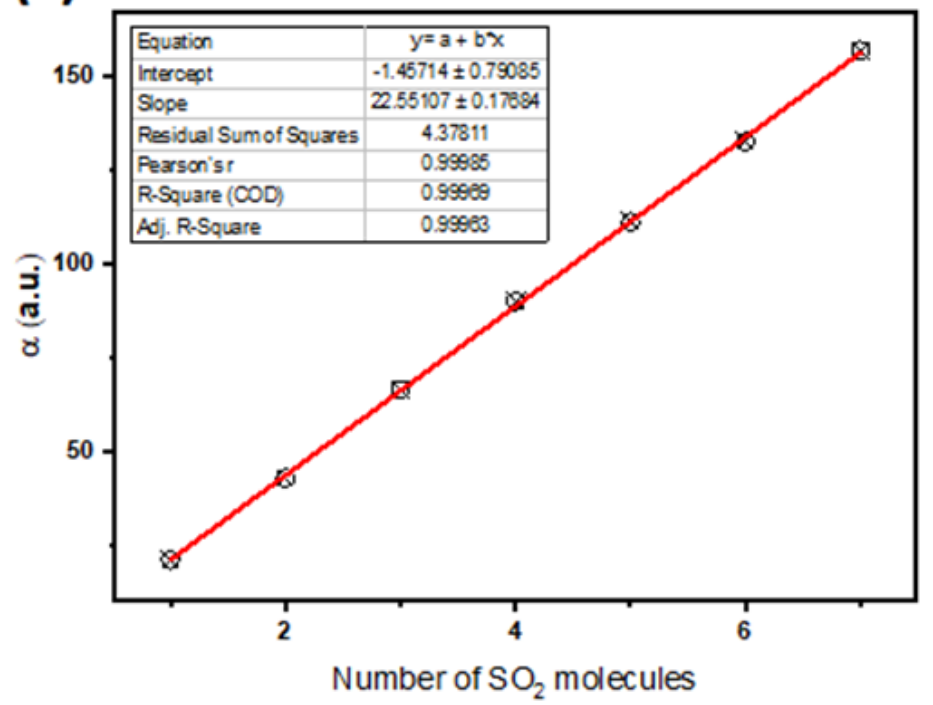

(b)

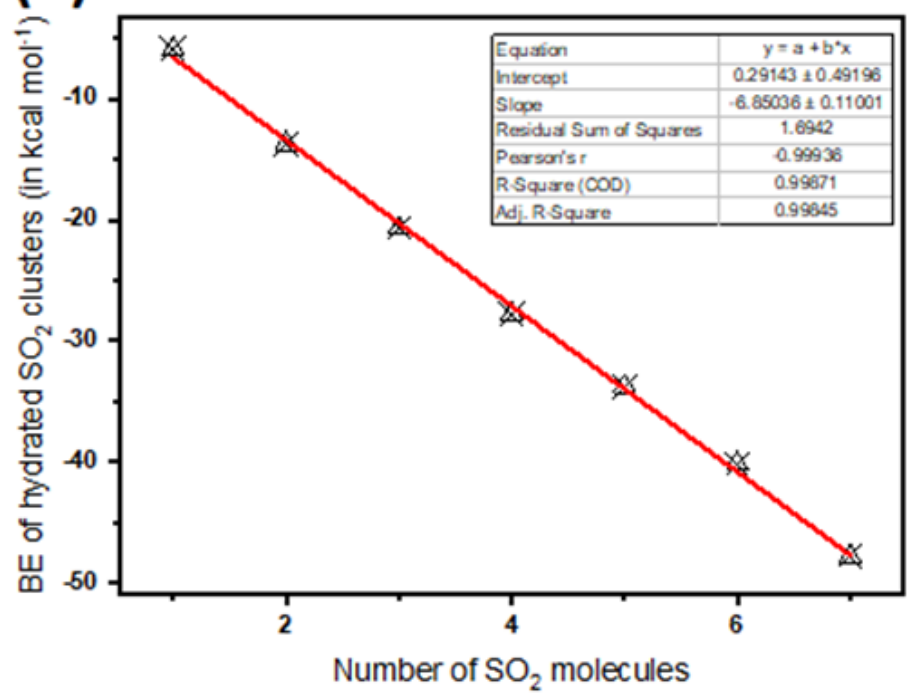

(d)

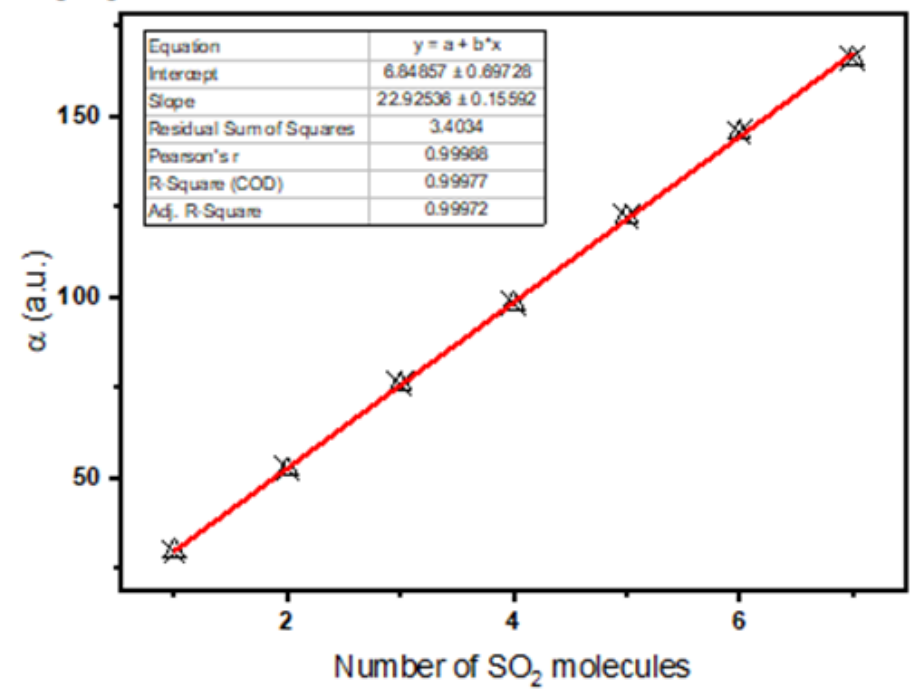

Figure 3

The plot of (a) total binding energy as a function of SO2 molecules for sulfur dioxide clusters (b) total binding energy as a function of SO2 molecules for hydrated sulfur dioxide clusters (c) mean polarizability as a function of SO2 molecules for sulfur dioxide clusters (d) mean polarizability as a function of SO2 molecules for hydrated sulfur dioxide clusters 

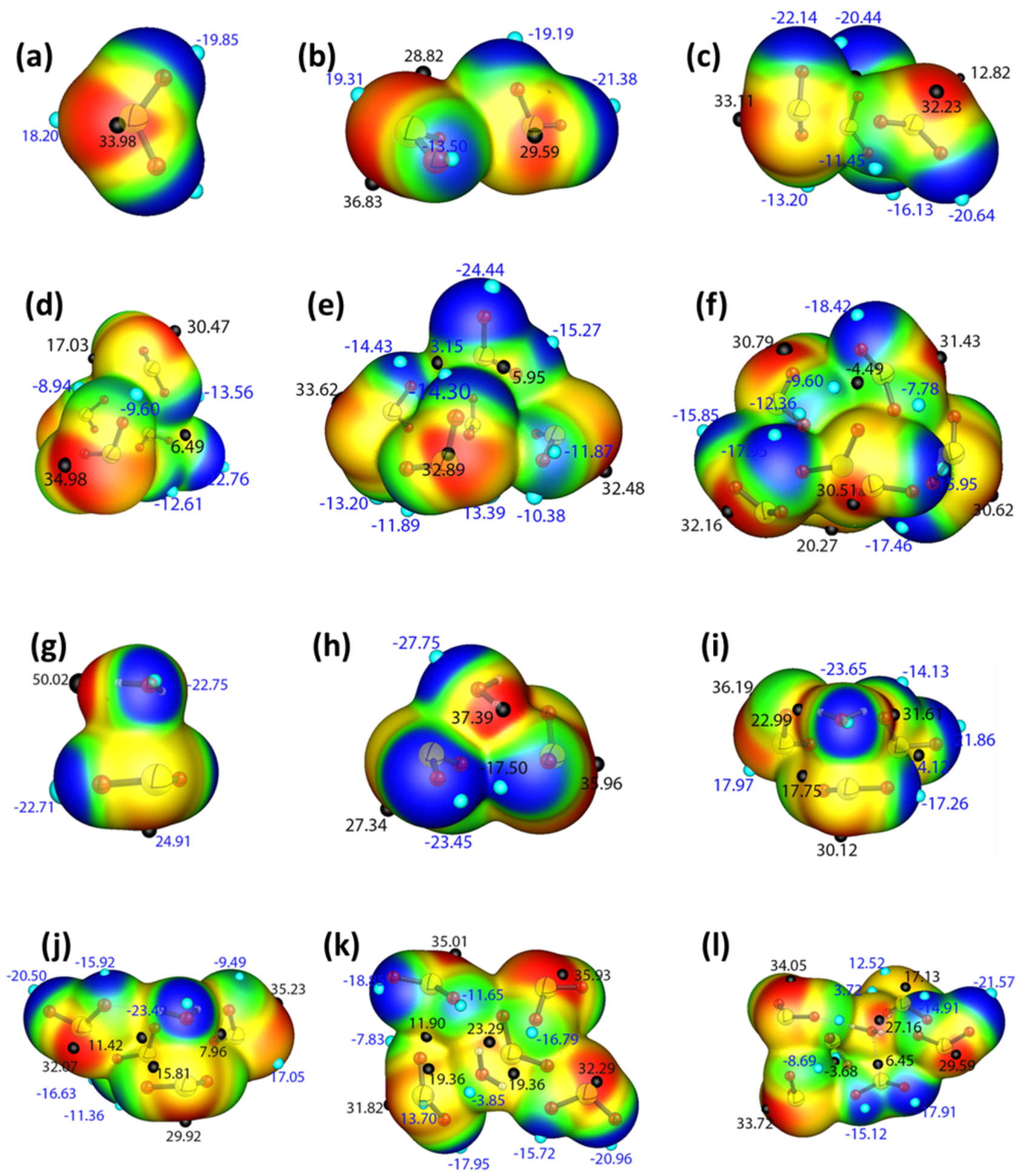

\section{Figure 4}

Electrostatic potentials for PGM (a) sulfur dioxide (b) dimer (c) trimer (d) tetramer (e) pentamer (f) hexamer (g) heterodimer (h) heterotrimer (i) heterotetramer (j) heteropentamer and (k) hetrohexamer (l) hetroheptamer clusters. Blue regions indicate a positive potential, and negative potentials are indicated by red regions. Contours are shown at the 0.001 au level. The potential values are given in kcal mol-1 
(a)

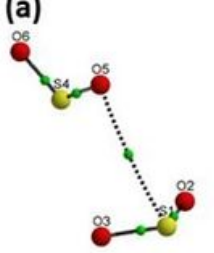

(b)

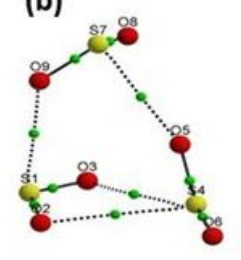

(g)

(h)

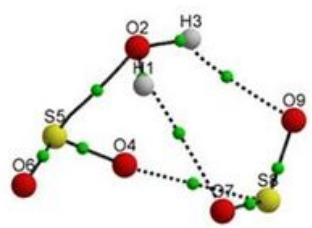

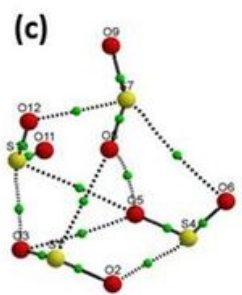

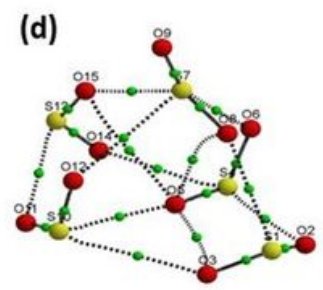

(i)

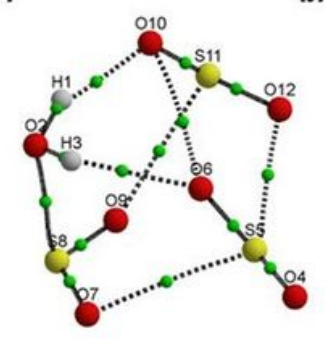

(j)
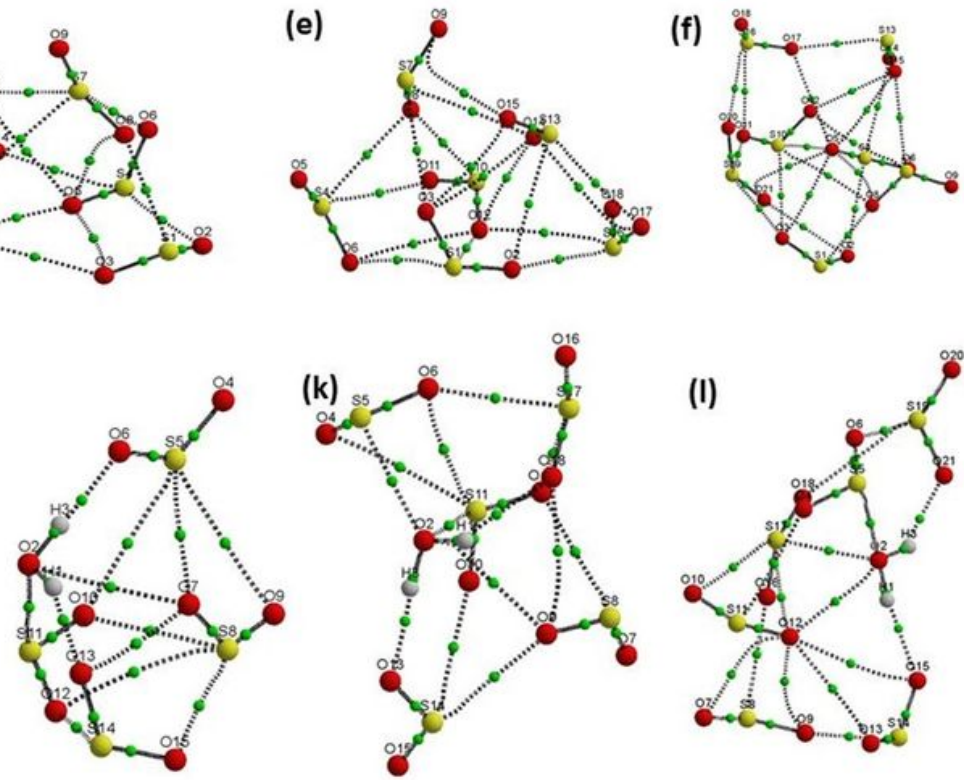

Figure 5

Molecular topography analysis for the PGM (a-f) SO2 and (g-l) hydrated SO2 clusters 

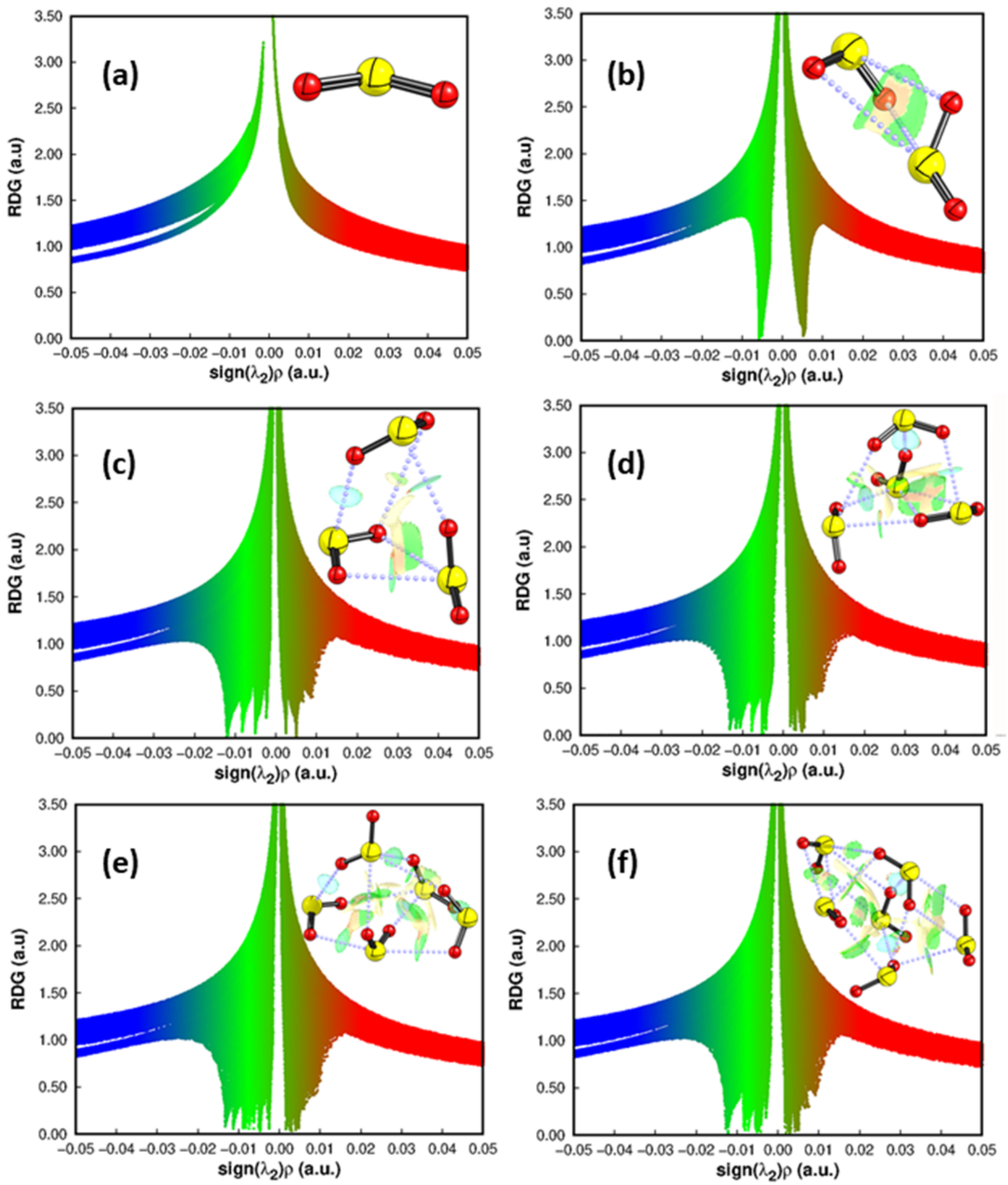

\section{Figure 6}

Plots of the reduced density gradient (s) versus $\operatorname{sign}(\lambda 2) \rho$, and $\mathrm{NCl}$ isosurfaces at the right corner of each image $(s=0.50)$ for PGM sulfur dioxide clusters.

\section{Supplementary Files}

This is a list of supplementary files associated with this preprint. Click to download. 
- GraphicalAbstract.png

- SupportingInformation.docx 